\title{
Fault structure and mechanics of the Hayward Fault, California, from double-difference earthquake locations
}

\author{
Felix Waldhauser ${ }^{1}$ and William L. Ellsworth \\ U.S. Geological Survey, Menlo Park, California, USA
}

Received 1 December 2000; revised 13 June 2001; accepted 18 August 2001; published 28 March 2002.

[1] The relationship between small-magnitude seismicity and large-scale crustal faulting along the Hayward Fault, California, is investigated using a double-difference (DD) earthquake location algorithm. We used the DD method to determine high-resolution hypocenter locations of the seismicity that occurred between 1967 and 1998. The DD technique incorporates catalog travel time data and relative $P$ and $S$ wave arrival time measurements from waveform cross correlation to solve for the hypocentral separation between events. The relocated seismicity reveals a narrow, near-vertical fault zone at most locations. This zone follows the Hayward Fault along its northern half and then diverges from it to the east near San Leandro, forming the Mission trend. The relocated seismicity is consistent with the idea that slip from the Calaveras Fault is transferred over the Mission trend onto the northern Hayward Fault. The Mission trend is not clearly associated with any mapped active fault as it continues to the south and joins the Calaveras Fault at Calaveras Reservoir. In some locations, discrete structures adjacent to the main trace are seen, features that were previously hidden in the uncertainty of the network locations. The fine structure of the seismicity suggests that the fault surface on the northern Hayward Fault is curved or that the events occur on several substructures. Near San Leandro, where the more westerly striking trend of the Mission seismicity intersects with the surface trace of the (aseismic) southern Hayward Fault, the seismicity remains diffuse after relocation, with strong variation in focal mechanisms between adjacent events indicating a highly fractured zone of deformation. The seismicity is highly organized in space, especially on the northern Hayward Fault, where it forms horizontal, slip-parallel streaks of hypocenters of only a few tens of meters width, bounded by areas almost absent of seismic activity. During the interval from 1984 to 1998, when digital waveforms are available, we find that fewer than $6.5 \%$ of the earthquakes can be classified as repeating earthquakes, events that rupture the same fault patch more than one time. These most commonly are located in the shallow creeping part of the fault, or within the streaks at greater depth. The slow repeat rate of 2-3 times within the 15-year observation period for events with magnitudes around $M=1.5$ is indicative of a low slip rate or a high stress drop. The absence of microearthquakes over large, contiguous areas of the northern Hayward Fault plane in the depth interval from $\sim 5$ to $10 \mathrm{~km}$ and the concentrations of seismicity at these depths suggest that the aseismic regions are either locked or retarded and are storing strain energy for release in future large-magnitude earthquakes. INDEX TERMS: 7230 Seismology: Seismicity and seismotectonics; 7215 Seismology: Earthquake parameters; 8010 Structural Geology: Fractures and faults; 8020 Structural Geology: Mechanics; KEYWORDS: Hayward Fault, seismicity, earthquake relocation, fault structure, fault mechanics

\section{Introduction}

[2] The Hayward Fault is located on the eastern side of San Francisco Bay, California, and forms one branch of the San Andreas Fault system that accommodates the relative motion between the North American and Pacific plates. It extends for 85 $\mathrm{km}$ from south of Fremont on the south to San Pablo Bay on the north and traverses densely populated urban areas [Lienkaemper et al., 1991; Graymer et al., 1995] (Figure 1). The fault is considered the most probable source of a future major earthquake in the area [Working Group on California Earthquake Probabilities (WGCEP),

\footnotetext{
${ }^{1}$ Now at Lamont-Doherty Earth Observatory of Columbia University, Palisades, New York.

Copyright 2002 by the American Geophysical Union. 0148-0227/02/2000JB000084\$09.00
}

1999] and is arguably one of the most hazardous faults in the United States.

[3] The potential of the fault to rupture in large earthquakes is well documented by an M6.8 earthquake that occurred in 1868 and ruptured the surface at least $30 \mathrm{~km}$ from Fremont to somewhere north of San Leandro [Lawson, 1908; Radbruch-Hall, 1974; Bakun, 1999]. Recent studies suggest that the rupture may have extended as far north as Oakland [Lienkaemper and Borchardt, 1992] or Berkeley [Yu and Segall, 1996]. No other large historic earthquake has been unequivocally assigned to the Hayward Fault. An 1836 earthquake, long assumed to have ruptured the northern Hayward Fault, is now believed to have occurred $\sim 100 \mathrm{~km}$ to the SE, implying that the northernmost Hayward Fault has not ruptured since the region was settled beginning in 1776 [Bakun and Wentworth, 1997; Toppozada and Borchardt, 1998]. Paleoseismic observations from El Cerrito and the historical record suggest that the most recent large event on the northern Hayward Fault occurred 

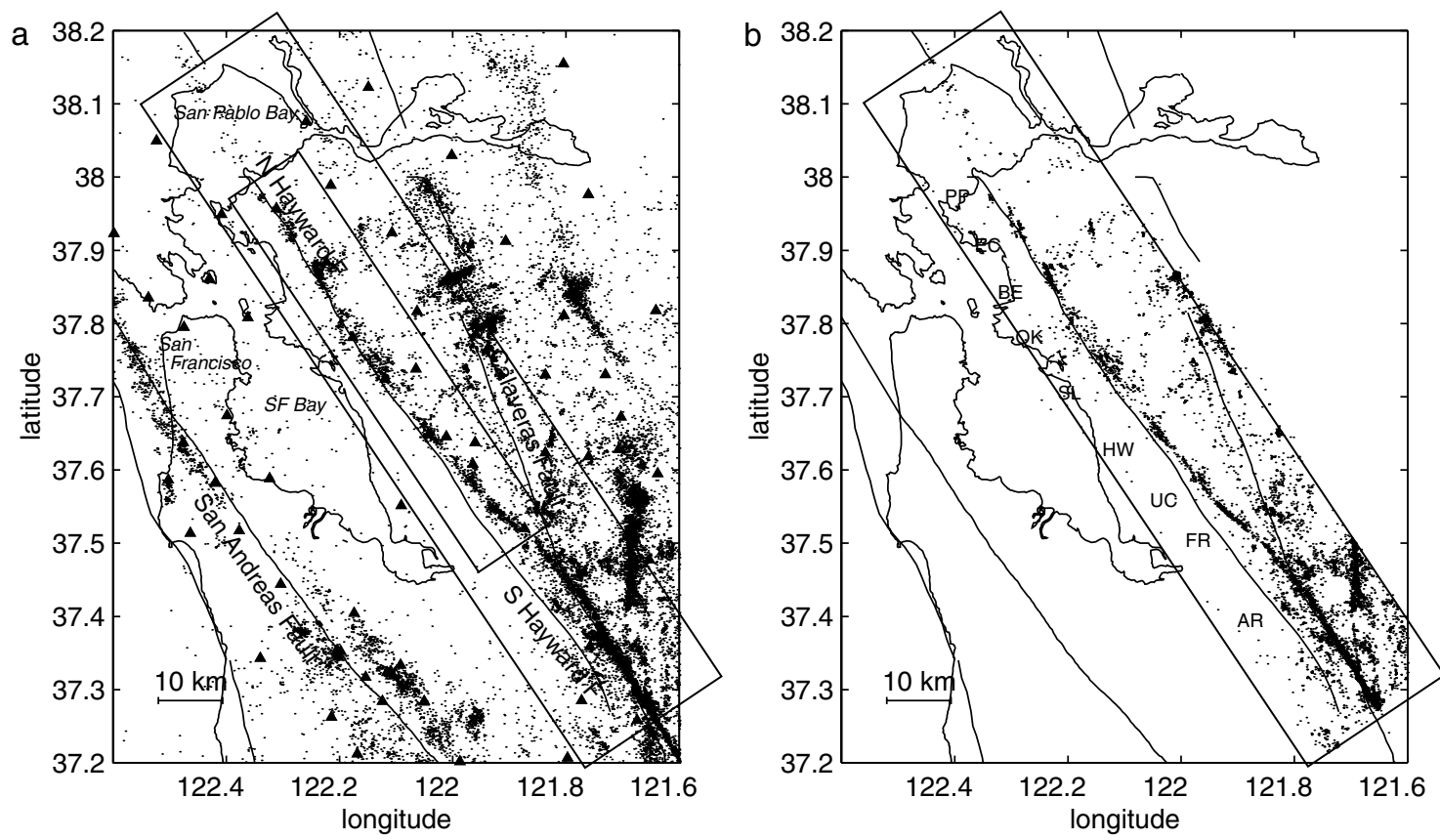

Figure 1. Overview of San Francisco Bay area faults and seismicity recorded by the Northern California Seismic Network (NCSN). (a) Earthquake locations by the NCSN. (b) Double-difference relocations using NCSN travel time data. Thin lines denote coast and fault lines, triangles in Figure 1a are stations used to relocate the earthquakes. PP, Point Pinole; EC, El Cerrito; BE, Berkeley; OK, Oakland; SL, San Leandro; HW, Hayward; UC, Union City; FR, Fremont; AR, Alum Rock. Boxes indicate areas investigated. Earthquake magnitudes within boxes range from $M 0.0$ to M5.8. The small box in Figure 1a includes events shown in Figure 5 and for which catalog and cross-correlation data were used for relocation.

between 1640 and 1776 [Hayward Fault Paleoearthquake Group, 1999]. Williams [1992] documented at least six Hayward Fault ruptures during the past 2100 years in a trenching study on the southern Hayward Fault near Fremont.

[4] At the surface the fault is creeping along its entire length [Lienkaemper et al., 1991], although the rate of creep varies spatially along the fault trace. A current average creep rate near the surface of $5 \mathrm{~mm} / \mathrm{yr}$ and an estimated long-term slip rate of $\sim 9$ $\mathrm{mm} / \mathrm{yr}$ suggest that $>1 \mathrm{~m}$ of slip has accumulated since the 1868 event, and thus $M>6.5$ events are now capable of occurring on the Hayward Fault [Lienkaemper et al., 1991; Savage and Lisowski, 1993].

[5] About 2000 events with coda duration magnitudes up to $M=4.6$ have been recorded since 1967 by the Northern California Seismic Network (NCSN) along the Hayward Fault (Figure 1, small box). Slip produced by these earthquakes and fault creep are not enough to accommodate the strain accumulation on the fault due to relative plate movement. The estimated 30 -year probability for rupture of the northern Hayward Fault by a M6.7 event is $16 \%$ and of the southern Hayward Fault is $17 \%$ [WGCEP, 1999]. Estimated cost and loss of life from such an event approach tens of billions dollars and several thousand deaths, respectively.

[6] The epicentral alignment of the recorded seismicity correlates well with the mapped surface trace of the fault especially north of San Leandro [Ellsworth et al., 1982; Oppenheimer et al., 1992; Castillo and Ellsworth, 1993] (Figure $1)$. The seismic activity takes place in almost equally spaced clusters along the fault with a separation distance of $10 \mathrm{~km}$ on average. Gravity and magnetic anomalies suggest that the locations of some of these clusters may correlate with the presence of mafic and ultramafic rocks within the fault zone [Ponce et al., 1998]. The clusters are from 2 to $8 \mathrm{~km}$ in length and are separated by quiet regions in which there is very little seismicity.
[7] The seismicity diverges from the mapped surface trace of the Hayward Fault south of San Leandro to follow a more easterly trend down to Fremont. This diverging strand of seismicity lies partly under the more northwesterly trending Mission Fault, although there is no throughgoing structure at the surface that follows the seismicity trend from the Hayward to the Calaveras Faults [Wong and Hemphill-Haley, 1992; Andrews et al., 1993; Graymer et al., 1995]. In this article we will refer to the diverging trend of seismicity as the "Mission trend." The adjacent principal surface trace of the Hayward Fault is nearly aseismic, although the most southern part of this portion of the fault exhibits the highest surface creep rate $(10 \mathrm{~mm} / \mathrm{yr})$ observed anywhere along the fault [Lienkaemper et al., 1991]. The cumulative seismic moment is significantly lower on the Mission trend than on the northern Hayward Fault for the time period 1984-1998. The Mission Fault has been hypothesized to accommodate the compressive strain in the left step over configuration between the Calaveras and the Hayward Faults [Andrews et al., 1993]. On the other hand, because of the lack of definite evidence of Holocene surface rupture, Wong and Hemphill-Haley [1992] associated the Mission seismicity to a seismically active buried trace of the Hayward Fault located east of its mapped surface trace.

[8] The factor of $\sim 2$ difference between the long-term slip rate and the observed surface creep rate, the sparse seismicity that is organized in patches on the fault plane, and the paleoseismic rupture history lead to the broadly accepted view that the Hayward Fault is accumulating strain at depth. For the northern Hayward Fault this view has recently been challenged as geodetic data indicate that the northern Hayward Fault north of Berkeley may be creeping at seismogenic depths [Bürgmann et al., 2000; Simpson, $2000]$.

[9] A major limitation in investigating the behavior of the Hayward Fault is the sparse seismicity and the lack of accurate information on the rupture process of the one large historical event. In a collection of papers published by the California 
Department of Conservation [Borchardt et al., 1992] the instrumental seismicity has been studied on the basis of earthquake locations routinely determined by the Northern California Seismic Network (NCSN). Although in some cases the events were relocated, it was not possible to observe any fine structure within the clusters or to discriminate between on-fault and off-fault seismicity. Recently, Waldhauser et al. [1999] imaged with high resolution the seismicity on the northern Hayward Fault using a double-difference earthquake location technique [Waldhauser and Ellsworth, 2000], revealing the surprising existence of horizontal streaks of hypocenters in the fault plane near Berkeley and El Cerrito.

[10] In this study we relocate the seismicity recorded between 1967 and 1998 by the NCSN along the Hayward and Mission Faults using hypoDD [Waldhauser, 2001], a program that implements the double-difference (DD) algorithm by Waldhauser and Ellsworth [2000]. We obtain relative location uncertainties that are in many cases smaller than the size of individual earthquakes (for $M>\sim 1.5$ ), which enables us to image the fine-scale structure of the seismically slipping surface. We use the new locations together with high-resolution focal mechanisms to find a wide range of complex seismicity patterns and style of faulting, which we analyze in terms of the structure and mechanics of the Hayward Fault system.

\section{Data Analysis}

[11] The DD earthquake relocation algorithm takes advantage of the fact that if the hypocentral separation between two earthquakes is small compared to the event-station distance and the scale length of velocity heterogeneity, then the ray paths between the source region and a common station are similar along almost the entire ray path [Fréchet, 1985; Got et al., 1994]. In this case, the difference in travel times for two events observed at one station can be attributed to the spatial offset between the events by differencing Geiger's equation for earthquake location [Waldhauser and Ellsworth, 2000]:

$$
\frac{\delta t_{i k}}{\delta \mathbf{m}} \Delta \mathbf{m}_{i}-\frac{\delta t_{j k}}{\delta \mathbf{m}} \Delta \mathbf{m}_{j}=\left(t_{i k}-t_{j k}\right)^{\mathrm{obs}}-\left(t_{i k}-t_{j k}\right)^{\mathrm{cal}}
$$

where the right-hand side is the difference between observed and calculated travel time difference between two events, $i$ and $j$, at station $k$ (a double difference), and $\Delta \mathbf{m}$ are the changes required in the hypocentral parameters to make the model better fit the data. The partial derivatives of the travel times $t$ for events $i$ and $j$, with respect to their locations $(x, y, z)$ and origin times $(t)$, respectively, are calculated from a one-dimensional (1-D) layered velocity model for the current hypocenters and the location of the station where the $k$ th phase was recorded. We use the velocity model used for routine location by the NCSN for events on the Hayward Fault (Table 1). The $S$ velocity model is obtained by scaling the $P$ velocity model by a factor $1 / \sqrt{3}$. The use of a $1-\mathrm{D}$ model is appropriate since the DD algorithm cancels errors due to unmodeled velocity structure.

[12] DD equations are built to link each event to several neighboring events, so that all events are connected and the solution for the adjustment to each hypocenter can be determined simultaneously. The DD vector is minimized by weighted least squares using the conjugate gradient method (LSQR) [Paige and Saunders, 1982]. Solutions are found by iteratively adjusting the vector difference between hypocentral pairs [Waldhauser, 2001]. When the earthquake location problem is linearized using the DD equations, the common mode errors cancel, principally those related to the receiver-side structure. Thus we avoid the need for station corrections or high-accuracy predicted travel times for the
Table 1. One-Dimensional $P$ Velocity Model

\begin{tabular}{cc}
\hline Top of Layer, $\mathrm{km}$ & $\mathrm{V}_{p}, \mathrm{~km} / \mathrm{s}$ \\
\hline 0 & 3.77 \\
1 & 4.64 \\
3 & 5.34 \\
6 & 5.75 \\
14 & 6.22 \\
25 & 7.98 \\
\hline
\end{tabular}

portion of the ray path that lies outside the focal volume. Details of the DD algorithm are given by Waldhauser and Ellsworth [2000].

[13] We use ordinary phase picks from the NCSN earthquake catalog together with high-precision differential travel times from phase correlation of $P$ and $S$ waves. The former are expressed as differential travel times so that the same equation is used for all data. The combined use of both catalog and cross-correlation data permits the simultaneous relocation of all events, with interevent distances within clusters of correlated events (multiplets) determined to the accuracy of the cross-correlation data, whereas relative locations between the multiplets and uncorrelated events are determined to the accuracy of the absolute data.

\subsection{Catalog Travel Time Differences}

[14] Travel times routinely computed from $P$ wave arrival times of $\sim 13,800$ events recorded by the NCSN between 1967 and 1998 near the Hayward/Mission Faults (see large box in Figure 1) are differenced for pairs of earthquakes at each station that observed both events. The travel time differences are selected to build a network of pair-wise connected events in which any event is linked to a maximum of 10 neighboring events by at least eight pair-wise observations, so that all events are simultaneously relocated relative to each other. An NCSN pick quality of 0,1 , or 2 is used. Only event pairs with hypocentral separation $<10 \mathrm{~km}$ are considered to keep the effect of ray path differences outside the source region small [Waldhauser and Ellsworth, 2000].

[15] Figure 2a shows $\sim 250,000$ selected catalog travel time differences as a function of separation distance obtained from events on the Hayward and Mission Faults for the time period 1984-1998 using 260 stations; $99.7 \%$ of the catalog travel-time differences are smaller than the maximum travel time difference expected for a given event pair offset when the station lies on the line connecting both events. Travel time differences are close to $0 \mathrm{~s}$ at zero event pair offset and generally smaller than $\sim 2 \mathrm{~s}$ at offsets of $10 \mathrm{~km}$, indicating an average source region velocity of $\sim 5 \mathrm{~km} / \mathrm{s}$. Data above the indicated straight line in Figure 2a are considered to be outliers and are removed before relocation. The concentration of outliers near the zero offset (Figure 2b) is due to the increased number of observations for nearby events in our sampling scheme. Outliers that occur within the triangular area below the line, however, cannot be detected by this approach. Theoretically, we could detect these outliers by predicting travel time differences based on the offset of an event pair and its relative orientation to a specific station. For a horizontally aligned event pair, for example, delay times plotted against observation azimuth describe a sine curve with the amplitude scaled by the length of the offset. However, the uncertainty in the catalog locations, and thus the uncertainty in the orientation of the event pair, is too large to detect such outliers efficiently. We remove these outliers during relocation.

\subsection{Cross-Correlation Travel Time Differentials}

[16] In addition to the catalog travel time differences for events that are on or close to the Hayward/Mission Faults (small box in Figure 1a) we measure travel time differentials for each event pair with waveforms that correlated at a common station using the cross-spectral method described by Poupinet et al. [1984]. Identi- 

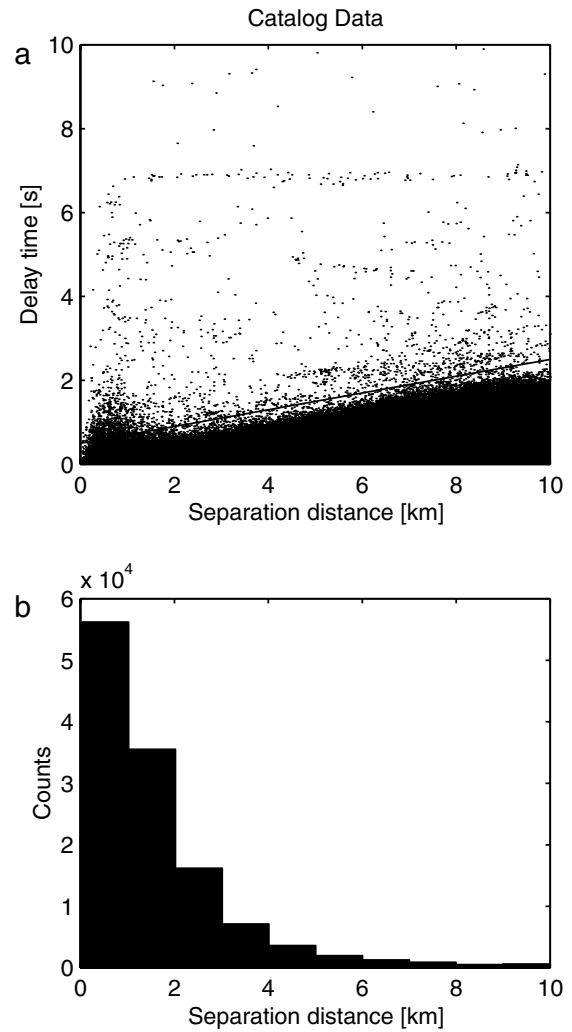

Figure 2. (a) Catalog travel time differences for event pairs as a function of the distance between the events, computed for $\sim 1700$ events recorded along the Hayward Fault between 1984 and 1998. Travel time differences above the straight line are considered outliers. The straight line represents travel time differences between two events computed with a constant source region velocity of $5 \mathrm{~km} / \mathrm{s}$. The line is shifted by $0.5 \mathrm{~s}$ along the time axis to account for possible uncertainties in the catalog locations. (b) Number of measured travel time differences as a function of distance between the events.

cal waveforms occur when the sources have a common slip surface (i.e., a repeating earthquake). Waveform similarity decreases with event pair separation because of increasingly different wave propagation paths and/or focal mechanisms and generally breaks down after the separation distance exceeds roughly the first Fresnel zone ( $\sim 300 \mathrm{~m}$ for $5-\mathrm{Hz} P$ waves). We use the digital waveforms recorded on vertical component seismometers and archived since 1984 by the NCSN. Stations at distances of up to $200 \mathrm{~km}$ from the event pair centroid are used. Two waveforms recorded at a specific station are considered similar when half of the squared coherency values, in the frequency range $2-10 \mathrm{~Hz}$, of a tapered 2.56-s (256 samples) window containing the $P$ wave ( $S$ wave) train, exceed 0.9. For two similar waveforms the time difference is proportional to the slope of the phase of the cross spectrum [Poupinet et al., 1984]. For sufficiently similar signals a precision of $1 \mathrm{~ms}$ can be achieved for the measurement of time differences in the energy of $P$ and $S$ arrivals from data digitized at 10-ms intervals [Poupinet et al., 1984; Fréchet, 1985].

[17] The distributions of coherency values for 56,000 measured $P$ and $S$ wave differential travel times are shown in Figure $3 a$. Both distributions feature a peak at 0.9 coherency, indicating the high quality of the data. Outliers are difficult to detect prior to relocation, but we can assess the consistency between the $P$ and $S$ wave data. For a given event pair and station we expect $P$ and $S$ wave delay times to be either negative or positive, i.e., exhibiting either a delay or an advance of the travel time of one event with respect to the other. In $3.2 \%$ of the data with both $P$ and $S$ wave measurements, however, we observe sign changes between $P$ and $S$ delay times. The distribution of the differences between $P$ and $S$ delay times of these inconsistent data (Figure 3 b) shows that $20 \%$ of the data have a difference between $P$ and $S$ delay times $<5 \mathrm{~ms}$, reflecting measurement uncertainties for close-by events rather than outliers. Data in the tails of Figure $3 b$ represent outliers (e.g., misaligned phases), either in the $P$ wave or the $S$ wave data, or both. Coherency values of these data, however, are typically low, and the measurements will therefore be downweighted during relocation.

\subsection{Data Weighting}

[18] The catalog data are downweighted by a factor of 100 relative to the cross-correlation data. Cross-correlation data are a priori weighted by the squared coherency catalog data by weights of $1,0.75$, and 0.25 for NCSN pick qualities 0,1 , and 2. Equal weights are used for $P$ and $S$ wave cross-correlation data. Residuals are reweighted after each iteration according to the misfit and the distance between events [Waldhauser and Ellsworth, 2000] (Figure 4). Catalog and cross-correlation data are removed/ reweighted for event pairs with separation distances larger/smaller than 10 and $2 \mathrm{~km}$, respectively. Weights are highest for close-by events and drop exponentially with increasing separation distance. Residuals larger than 6 times the median absolute deviation from the median of each data type are considered outliers and discarded. When using both data types simultaneously, one has to be aware that the first-motion arrival times image the point of rupture initiation (hypocenter), whereas cross-correlation data image the
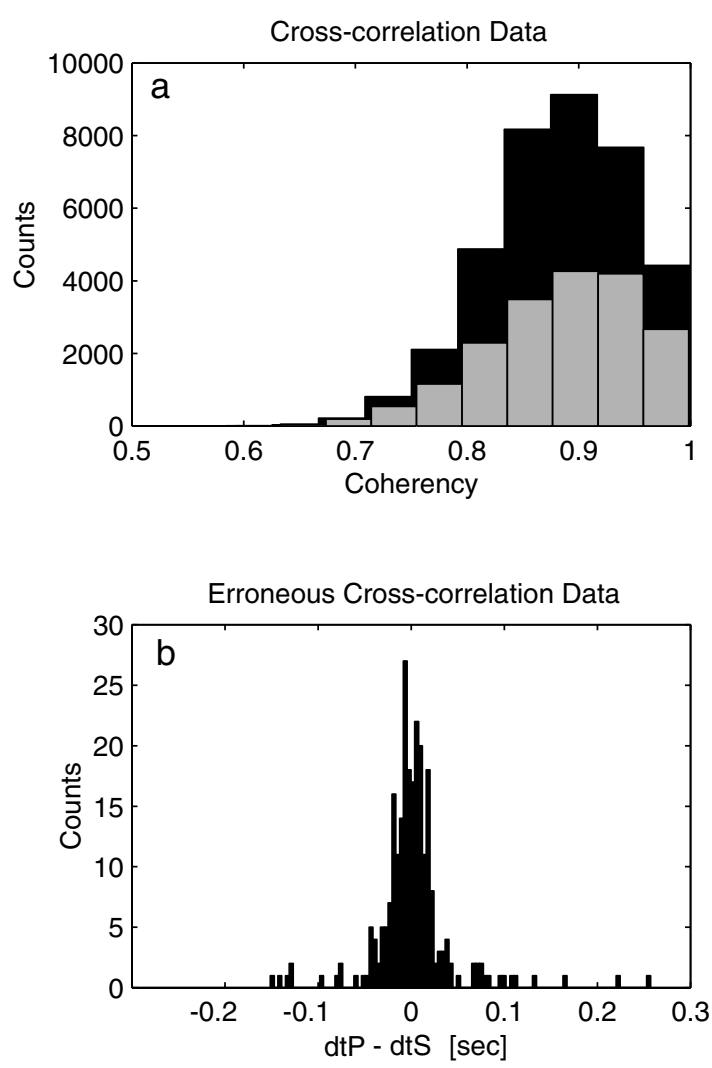

Figure 3. Quality and distribution of cross-correlation data. (a) Histogram of coherency values of $P$ phases (solid) and $S$ phases (shaded) used to determine travel time differences between events at common stations. (b) Distribution of the differences in travel time differences between cross-correlation $P$ and $S$ wave data for pairs of events that have opposite signs at a common station. 


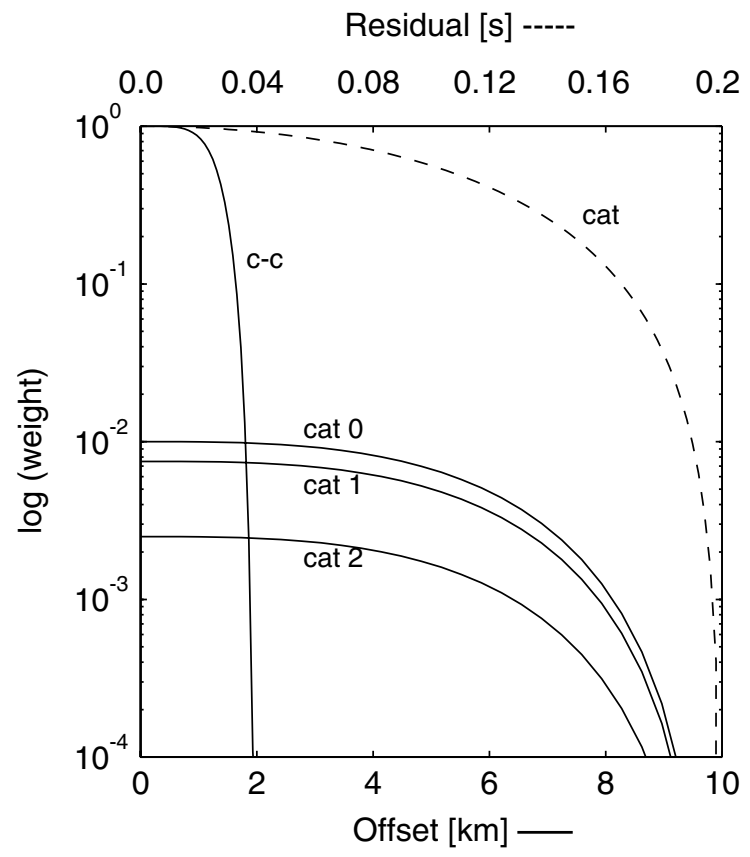

Figure 4. Reweighting functions used to downweight/reject data with large distances between the events (shown for crosscorrelation data, $2 \mathrm{~km}$, and catalog data, $10 \mathrm{~km}$, of different weight classes; solid lines) and/or large residuals (shown for catalog data only and a typical rejection threshold of $0.2 \mathrm{~s}$; dashed line). From Waldhauser and Ellsworth [2000].

center of moment release (hypocentroid) as the cross spectra of entire $P$ or $S$ phases are used to estimate the time delays between the event arrivals.

\section{Relocation Results}

[19] While catalog $P$ wave travel times are available for events that date back as far as 1967, digital waveforms were archived by the NCSN only from 1984. To account for the different time periods and data quality, we perform two sets of relocations. The first set includes catalog data of 13,764 well-located and wellconnected events $(84 \%$ of the events listed in the catalog) that occurred between 1967 and 1998 and are located within a larger area encompassing the Hayward/Mission Fault system (large box in Figure 1a). The epicenter distribution of the 13,598 relocated events is shown in Figure 1b. Events get deleted during relocation when they loose linkage to neighboring events due to outlier removal. The RMS residual decreased by $\sim 75 \%$ from 78 to 18 $\mathrm{ms}$ after relocation.

[20] The second set includes catalog and waveform data of events between 1984 and 1998 that are located on the Hayward/ Mission Faults or are within $\sim 10 \mathrm{~km}$ of the surface trace of the Hayward Fault (Figure 5a). The combined data set of $\sim 300,000$ delay time observations enables us to relocate $97 \%$ of the 1251 hypocenters listed in the NCSN catalog (Figure 5b). Most of the excluded events do not have waveforms and/or have only few and low-quality first-arrival picks. Sixty-two percent of the events have at least four cross-correlation measurements. In Figure 5b, groups of eight or more events with highly correlated waveforms are indicated in red and labeled. Routine locations for correlated events are dramatically improved by including the phase correlation measurements, with RMS error decreasing by $95 \%$ from 110 to $5 \mathrm{~ms}$. The RMS error for catalog $P$ wave data decreased by $50 \%$ to $\sim 54 \mathrm{~ms}$. The mean shifts in horizontal and vertical direction during relocation are 250 and $520 \mathrm{~m}$, respectively. In comparison, the average horizontal and vertical uncertainties in the routine locations are 370 and $680 \mathrm{~m}$, respectively. In general, the error estimates in hypocenter location decreased by an order of magnitude. The resolution estimates reflect the relative location uncertainty, but the absolute location uncertainty might be larger.

[21] The improvement in relative hypocenter location is, to first order, due to the use of travel time differences as the data, which minimizes common model travel time errors [Waldhauser and Ellsworth, 2000]. The further improvement of the correlated events is due to the increased accuracy with which cross-correlation techniques measure $P$ and $S$ wave delay times $(\sim 1 \mathrm{~ms})$. This is particularly important for $S$ waves for which absolute arrivals cannot be identified on the vertical component seismograms but for which the relative travel time for two similar events can easily be measured with cross correlation.

[22] In map view the relocated seismicity reveals a narrow fault zone at most locations along the Hayward and Mission trends. In some locations, discrete structures adjacent to the main trace are seen, features that were previously hidden in the uncertainty of the routine locations (Figures 1 and 5). Near San Leandro, where the more westerly striking Mission seismicity trend intersects the Hayward Fault, the seismicity remains diffuse, indicating a more volumetric zone of deformation to the northwest of the main trace of the Hayward Fault. Most of the on-fault seismicity collapses into narrow lines of epicenters that are oriented in the general direction of the trend of the seismicity (Figure 5b). Off-fault activity is notable near Berkeley where the seismicity forms tight clusters to the east of a well-defined Hayward Fault surface. The southern Hayward Fault as mapped at the surface is aseismic except for a small cluster of events slightly to the northeast of the fault near Alum Rock (AR, Figure 1). Few earthquakes are located southwest of the Hayward Fault.

[23] Fault-parallel cross-sectional views of the on-fault seismicity indicate that most of the events are located within a depth range of $\sim 3-13 \mathrm{~km}$ (Figure $5 \mathrm{~b}$ ). The maximum depths are more constant on the Hayward Fault than on the Mission trend. Most of the earthquakes cluster in patches on the fault surface, with large regions devoid of detectable earthquakes adjacent to the clusters. The aseismic regions at depths shallower than $\sim 4 \mathrm{~km}$ are believed to release stress primarily by creep [Savage and Lisowski, 1993]. Creep is likely to also occur in regions of the fault characterized by dense microseismicity.

[24] In fault-parallel cross section the relocated events reveal that only a small fraction of the fault plane slips seismically, compared to a much larger area that might be inferred from the catalog locations. This is mostly evident on the northern Hayward Fault between Point Pinole and Berkeley, where the relocated hypocenters form seismic streaks or lineations, alignments of hypocenters along one-dimensional horizontal structures (P1, E1, E2, B1, B2 in Figure 5b) [Waldhauser et al., 1999]. The streaks seem to bound holes, large areas where seismicity is sparse or absent. The seismicity on the Hayward Fault south of Berkeley and on the Mission trend is more scattered in depth, and fewer events correlate. Three small groups of correlated events in the San Leandro cluster form short southeast dipping streaks (S1, S2, S3 in Figure 5b) that parallel the Hayward Fault. These streaks, composed of $\sim 10$ events each and extending over a few hundred meters, are many times smaller in size and length than the ones observed farther north (several tens of events along $\sim 2000 \mathrm{~m}$ ). Although short, the horizontal alignment of the hypocenters is unambiguous. On the Mission Fault the distribution of correlated events is more diffuse. Near Hayward, the shallow multiplet $\mathrm{H} 1$ at $\sim 3 \mathrm{~km}$ depth seems to trend more westerly than the multiplet $\mathrm{H} 2$ at a depth of $\sim 6 \mathrm{~km}$ (Figure 5).

[25] Cross-sectional views perpendicular to the fault (Figure 5b) show that the general dip of the fault is near-vertical, although it dips slightly to the northeast near El Cerrito and Union City. While the seismicity on the northern Hayward Fault clearly underlies the 
a)
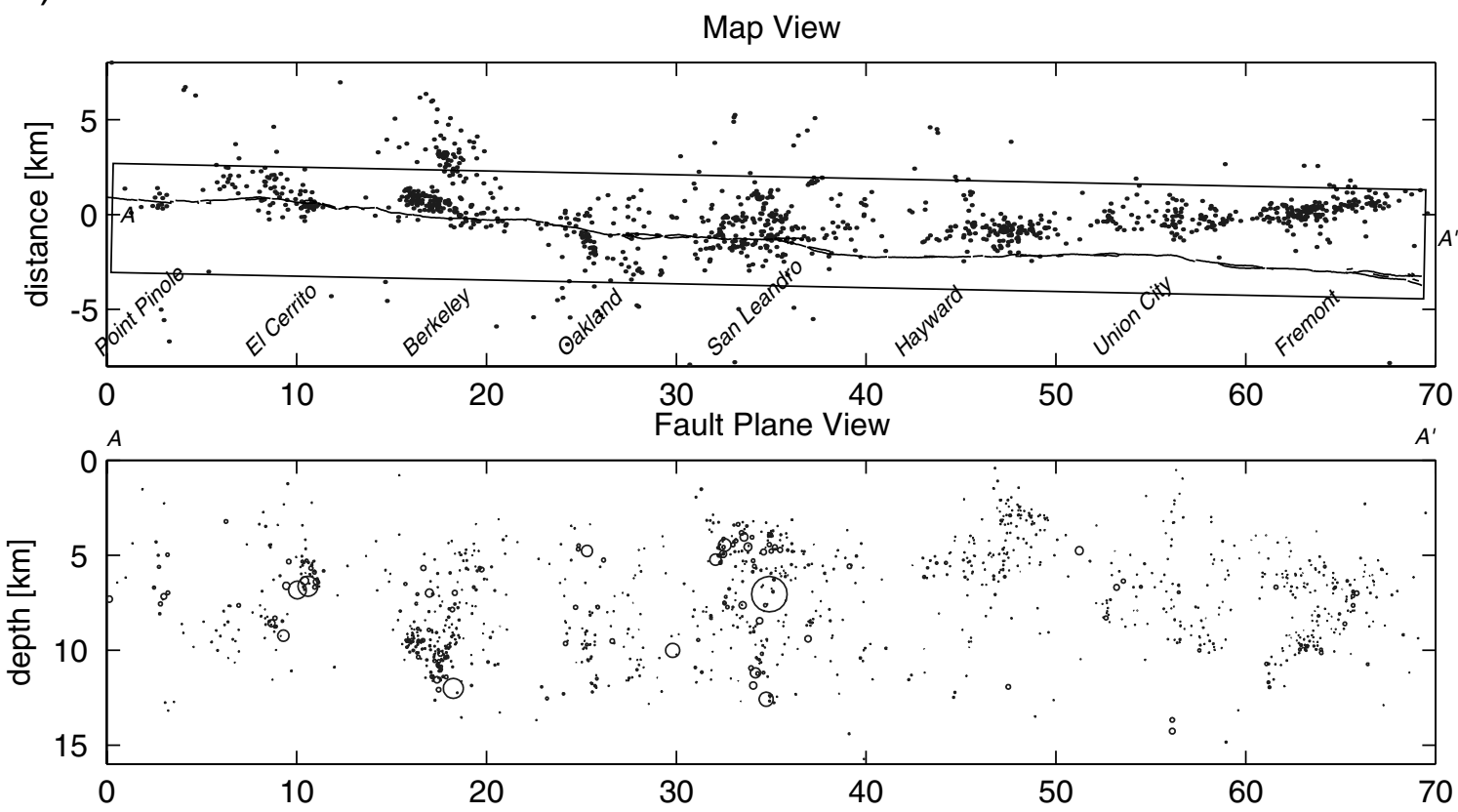

b)

AFTER RELOCATION

Map View
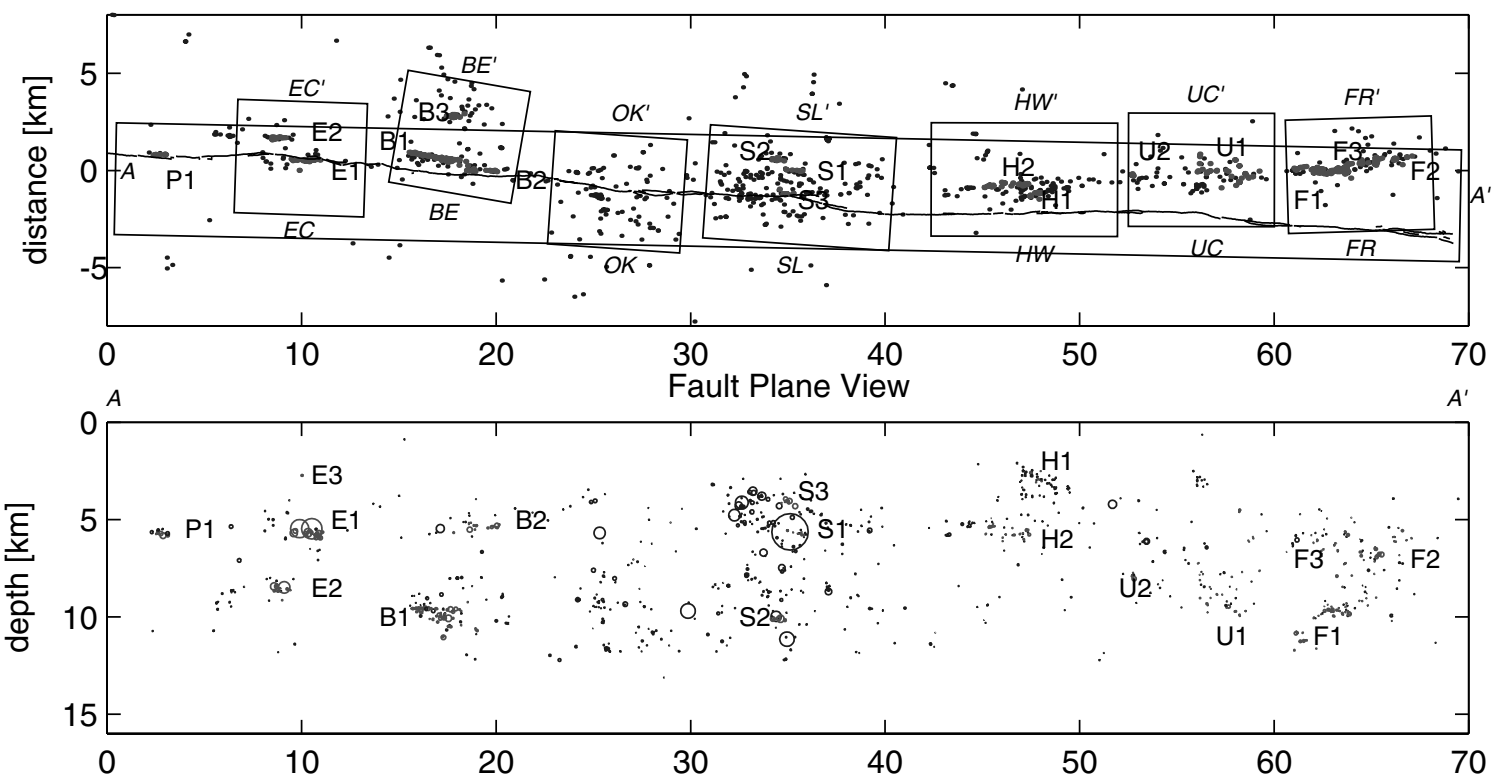

Fault Normal View
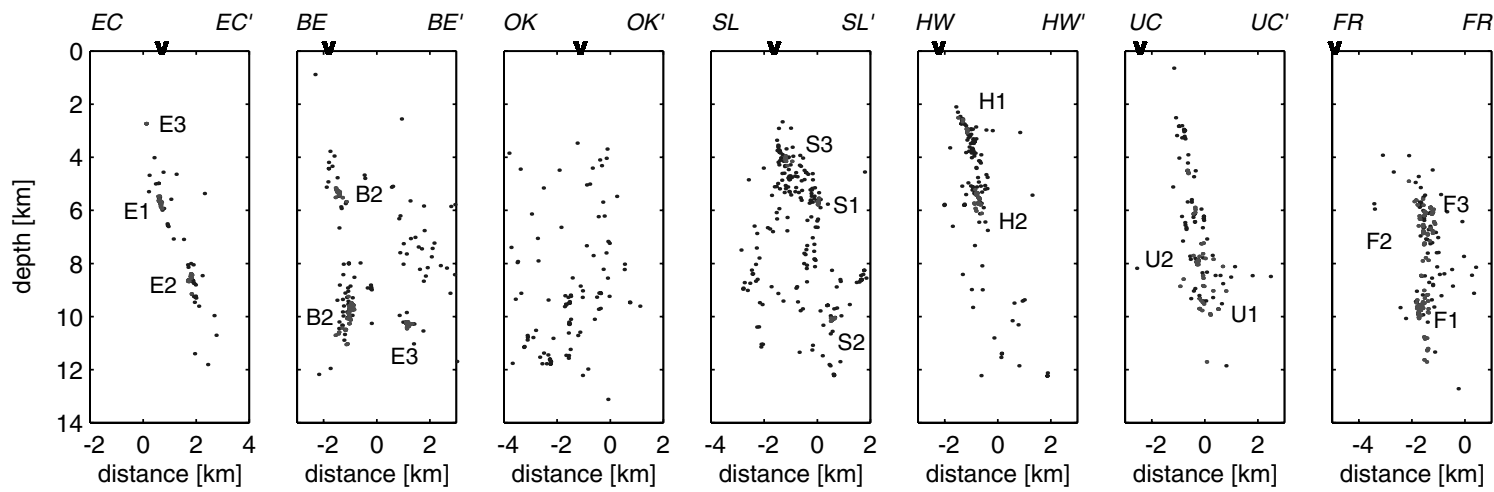

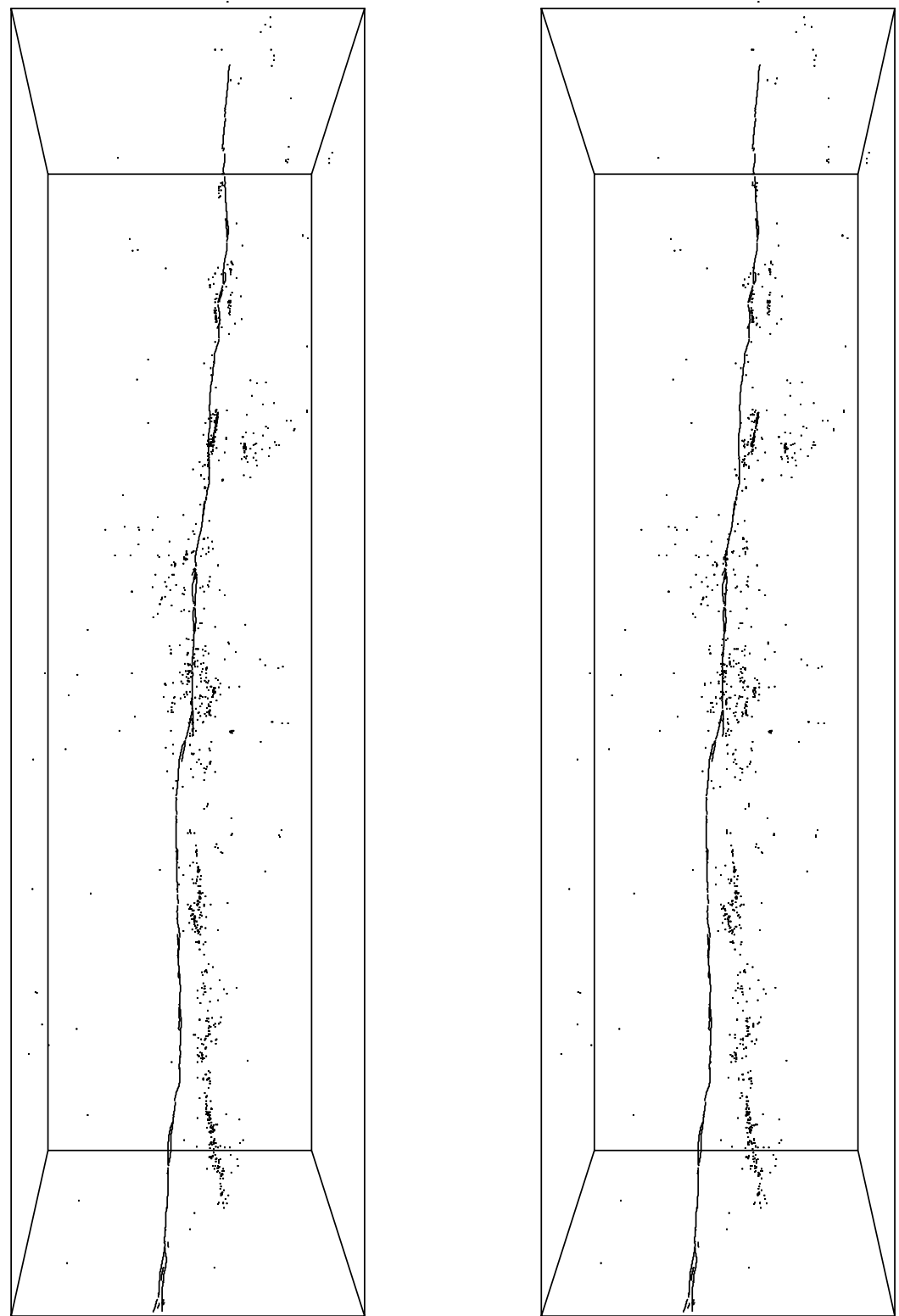

Figure 6. Stereoscopic plot of hypocenters. View is from $50 \mathrm{~km}$ above the surface near the San Leandro cluster in the middle of the box. Surface trace of the Hayward Fault is indicated. Size of box corresponds approximately to the small box shown in Figure 1a. View figure from $\sim 30 \mathrm{~cm}$ distance and try to superimpose the two boxes until it snaps into a 3-D view. Be patient.

surface trace of the fault, the association of seismicity and mapped fault trace south of San Leandro is less clear. The geometry of the seismically active fault is easily seen in a three-dimensional view of the hypocenters by means of stereoscopic plotting in Figure 6. At some locations, in particular, north of Oakland, the active fault zone is very narrow. The width of the streaks and presumably that of the active fault plane at these locations is generally $<200 \mathrm{~m}$.
Along streak B1 at a depth of $\sim 10 \mathrm{~km}$ the width is as small as 25 $\mathrm{m}$. Such narrow fault zones are consistent with geologic findings [Chester et al., 1993] and studies based on a comparison of plate rates to seismic moment release in the Bay area [King et al., 1994]. In contrast, the seismicity near San Leandro forms a large-scale inverted flower structure, with the width of the earthquake distribution at greater depth being many times larger than the mis-

Figure 5. (opposite) (a) NCSN locations and (b) double-difference locations of events recorded between 1984 and 1998 , including catalog $P$ and cross-correlation $P$ and $S$ wave data. Map view (rotated so that fault trace points east-west) and longitudinal cross sections (in kilometers from Point Pinole) are shown. Fault-normal cross sections are shown for the relocated seismicity only. Earthquakes in longitudinal cross sections are plotted as circles of dimensions appropriate for their magnitude assuming a 30-bar constant stress drop source. Boxes in map views include events shown in cross sections. In Figure 5b, groups of eight or more correlated events are indicated in red and labeled (see text for details). In fault-normal cross sections, "v" indicates the surface trace of the Hayward Fault. See color version of this figure at back of this issue. 


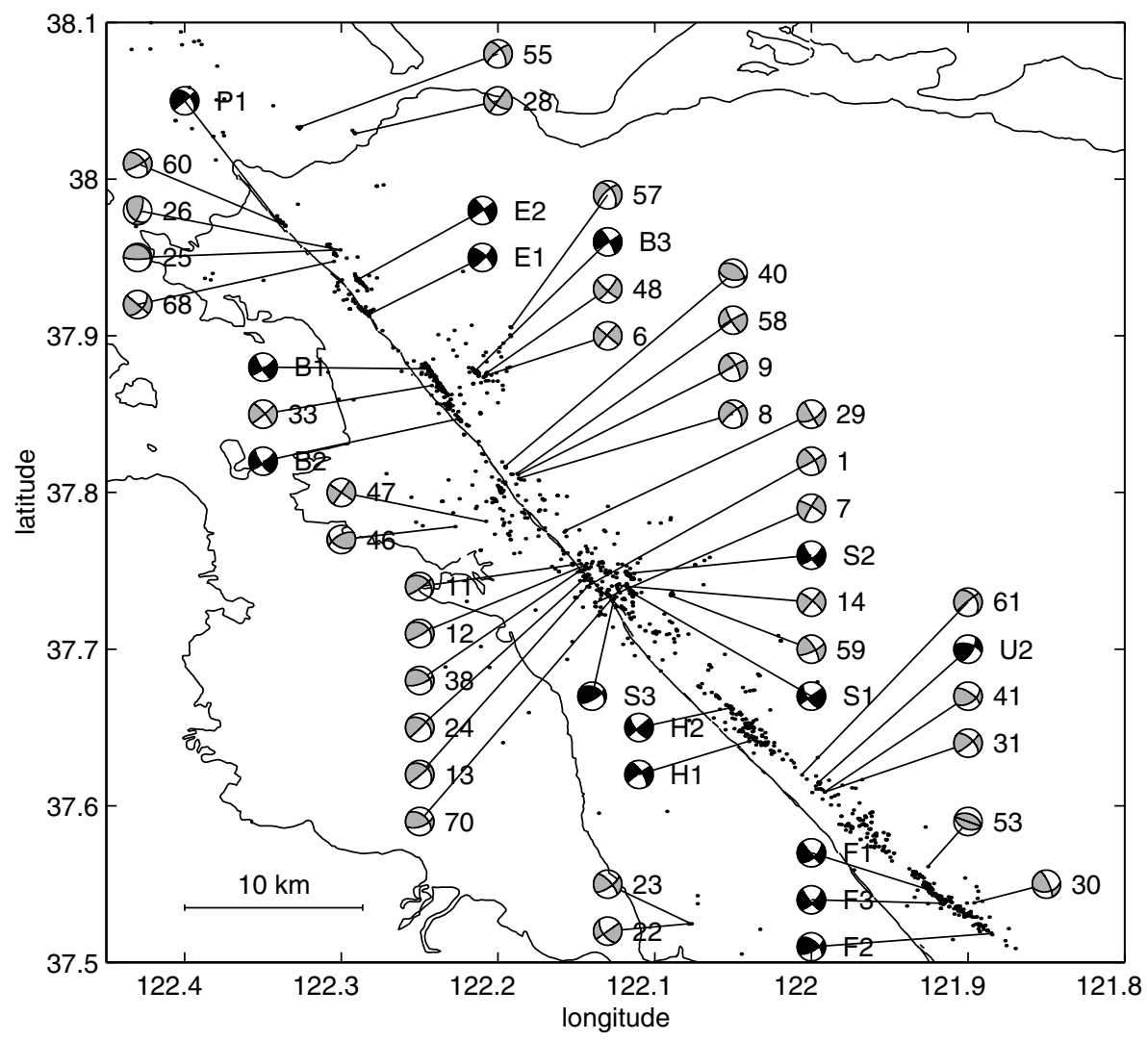

Figure 7. Epicenter distribution (dots) with single event (shaded) and composite focal mechanisms (solid). Thin lines denote coast lines and fault trace. See text for labels. Labels of composite mechanisms correspond to multiplet labels in Figure 5b.

location accuracy. This implies that the seismicity is occurring on structures adjacent to the Hayward Fault or that the fault consists of several substructures at this location. The short, southeast dipping streaks S1, S2, and S3 (Figure 5b) may represent the slip direction on such secondary faults.

\section{Focal Mechanisms}

[26] We compute well-constrained $P$ wave focal mechanisms having a minimum of 30 first-motion picks for selected $M>2.5$ events with the newly computed takeoff angles (Figure 7, shaded mechanisms). The mechanisms and 95\% confidence regions were determined using FPFIT, a least squares grid search procedure which minimizes the number of discrepant first motions [Reasenberg and Oppenheimer, 1985]. In addition to the single-event focal mechanisms we compute composite mechanisms (solid mechanisms in Figure 7) for events that belong to a multiplet. First motions of such correlated events are, in general, consistent, which is what we expect because of the high similarity of the waveforms. Hence variations in focal mechanisms of individual events within a multiplet are due to variations in the number of observations per event or errors in the reading and not due to variations in faulting. Thus we can enhance the solution of these events by computing composite mechanisms.

[27] The focal mechanisms displayed in Figure 7 show that the dominant style of deformation along the Hayward/Mission Faults is right-lateral strike slip on NW trending planes, with indication of convergent components near San Leandro and on the Mission Fault. Events on the northern Hayward Fault north of Oakland exhibit pure strike-slip motion, indicating a fault plane with a strike that is consistent with the trend of the seismicity and the surface trace. Small variations in the strike of the composite mechanisms for the streaks are consistent with the variation in streak orientation (Figure 8). We observe a trend of $\mathrm{N} 45^{\circ} \mathrm{W}$ for streak E1 near El Cerrito, while the fault plane solution gives a strike of $\mathrm{N} 41^{\circ} \mathrm{W}\left( \pm 5^{\circ}\right)$ (Figure 8a). Similarly, a trend of $\mathrm{N} 55^{\circ} \mathrm{W}$ is observed for the deeper streaks E2 near El Cerrito (Figure 8b) and B1 near Berkeley (Figure 8c), consistent with the strike of $\mathrm{N} 57^{\circ} \mathrm{W}\left( \pm 3^{\circ}\right)$ obtained from the fault plane solutions. Although streak P1 near Point Pinole is only $\sim 700 \mathrm{~m}$ in length, it exhibits a clear $\mathrm{N} 55^{\circ} \mathrm{W}$ direction which agrees with the fault plane solution at the $95 \%$ confidence level $\left(\mathrm{N} 50^{\circ} \mathrm{E} \pm\right.$ $5^{\circ}$ ) (Figure 8e). These results indicate that the trend of the deeper fault plane is $\sim 10^{\circ}$ more northerly than the shallow trend (see 3-D view in Figure 6). The change in strike occurs across the almost aseismic depth interval from 5 to $9 \mathrm{~km}$, indicating a curved fault surface or different structures on which the events occur. The streaks at shallow depths show a slight counterclockwise rotation in strike from southeast (Berkeley) to northwest (El Cerrito) (see mechanisms B2, E1, and 33 in Figure 7).

[28] The composite focal mechanism for the off-fault multiplet B3 near Berkeley as well as focal mechanisms from single events (6 and 48 in Figure 7) within that cluster all show shear parallel to the main trace of the Hayward Fault. This is different from what is observed, for example, on the creeping San Andreas Fault near Stone Canyon or along the Calaveras Fault [Zoback et al., 1987; Oppenheimer et al., 1988], where maximum stress orientations show fault normal compression off the fault, arguing for a weak rheology of these faults.

[29] The diffuse spatial distribution of the events and the strong variation in focal mechanisms between close-by events near Oakland and San Leandro argue for a highly fractured zone. Only $40 \%$ 
a)

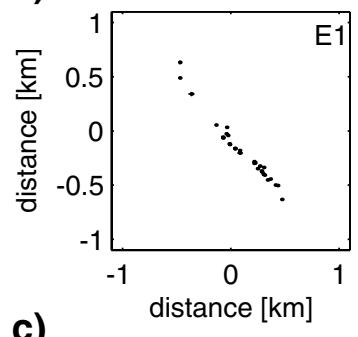

c)

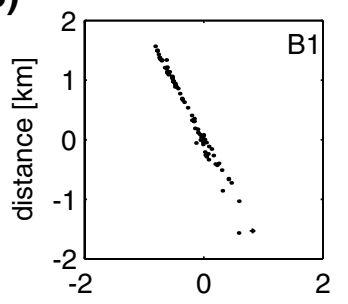

e)

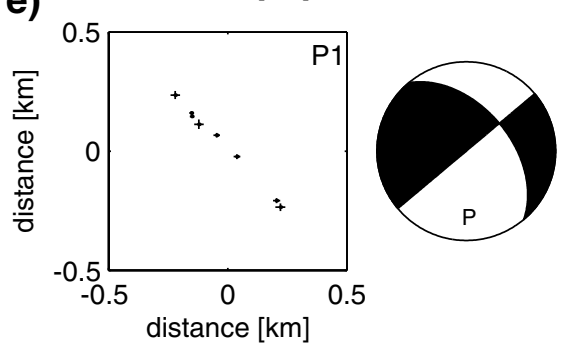

b)
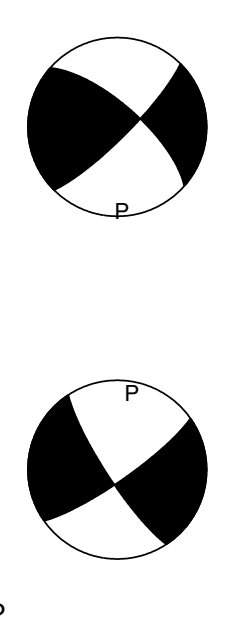

d)
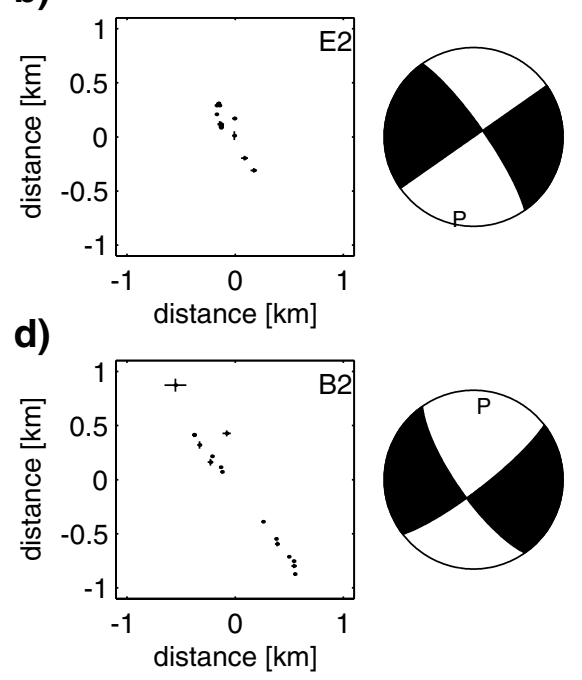

Figure 8. Map view of events and composite focal mechanisms of the streaks (a) E1, (b) E2, (c) B1, (d) B2, and (e) P1 on the northern Hayward Fault. Crosses indicate $2 \sigma$ errors.

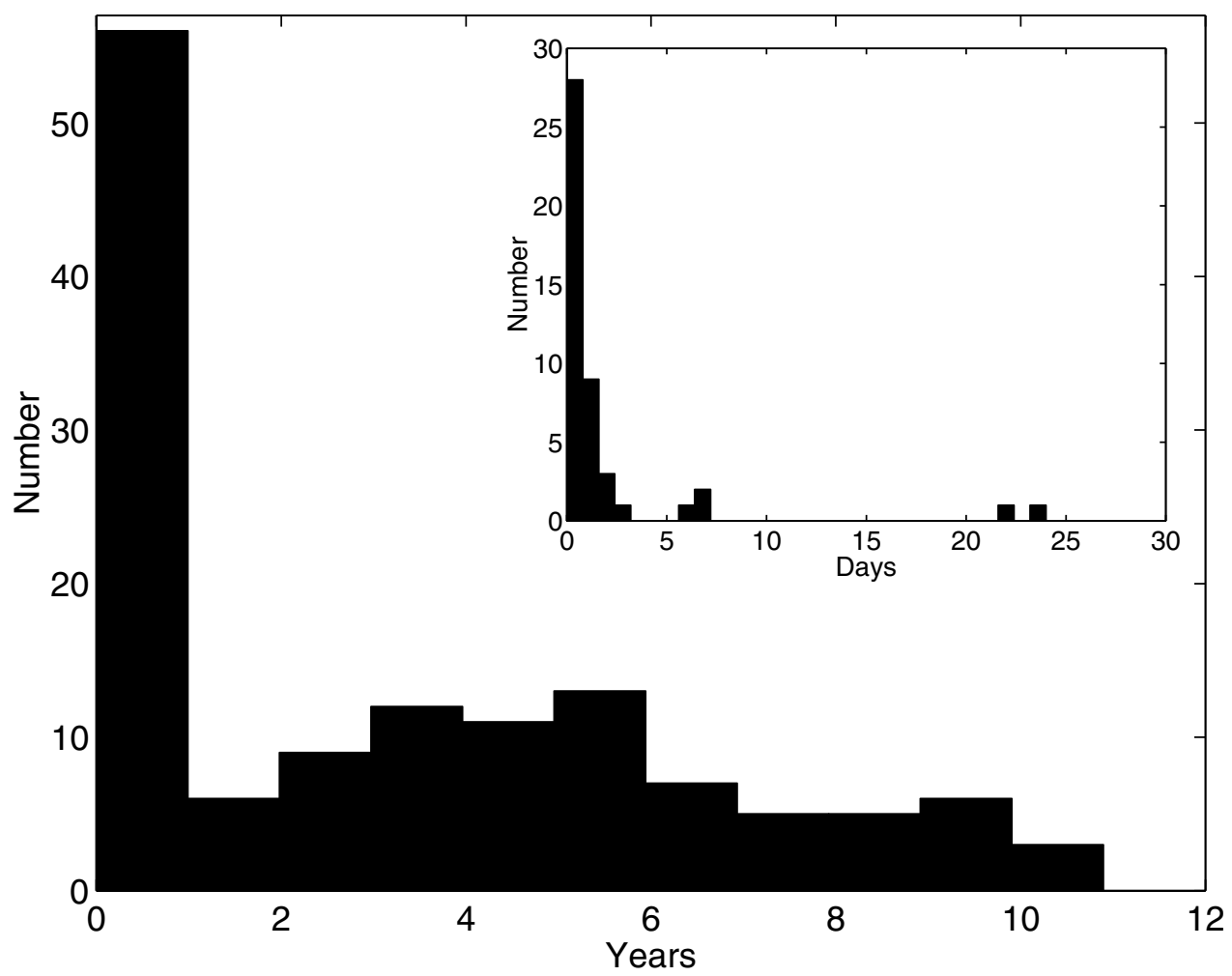

Figure 9. Histograms of recurrence intervals for all events on the Hayward/Mission Faults that are closeby and successive. Inset shows the distribution of intervals $<1$ month. 
a

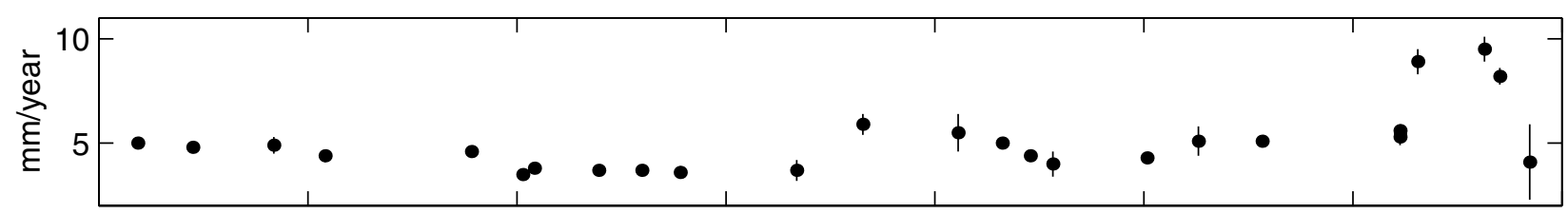

On Fault Seismicity

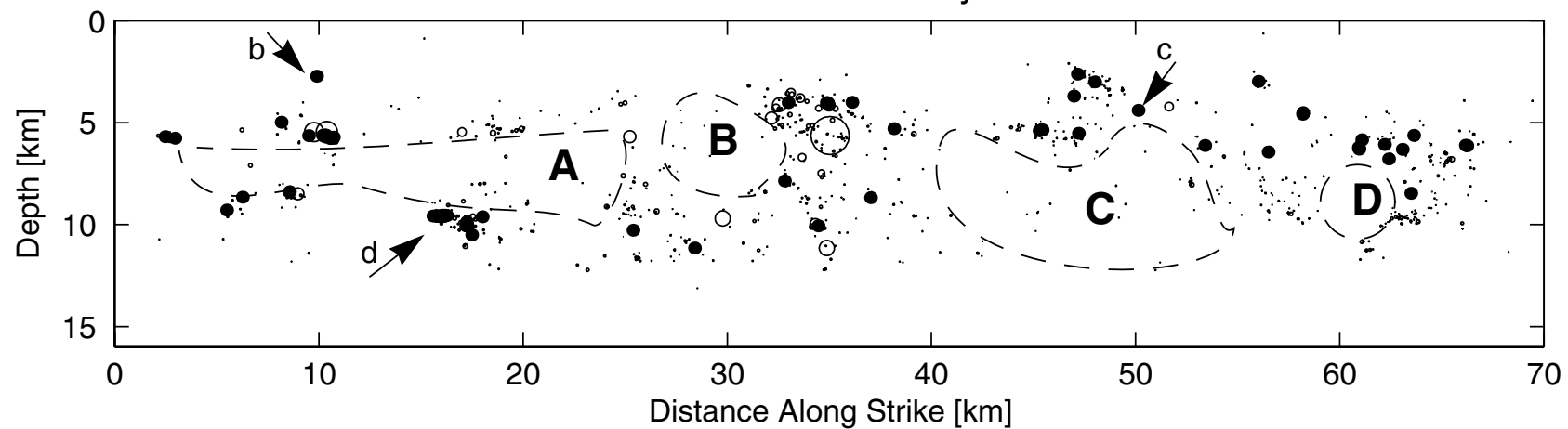

$\mathrm{b}$
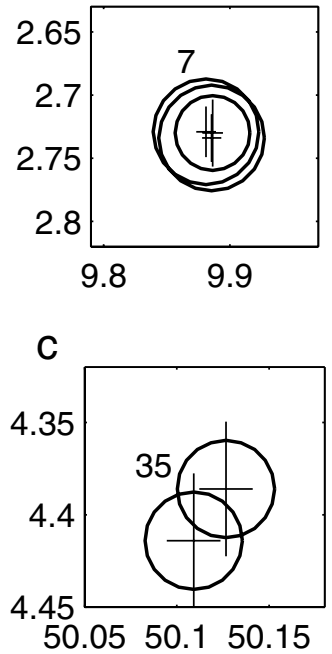

d

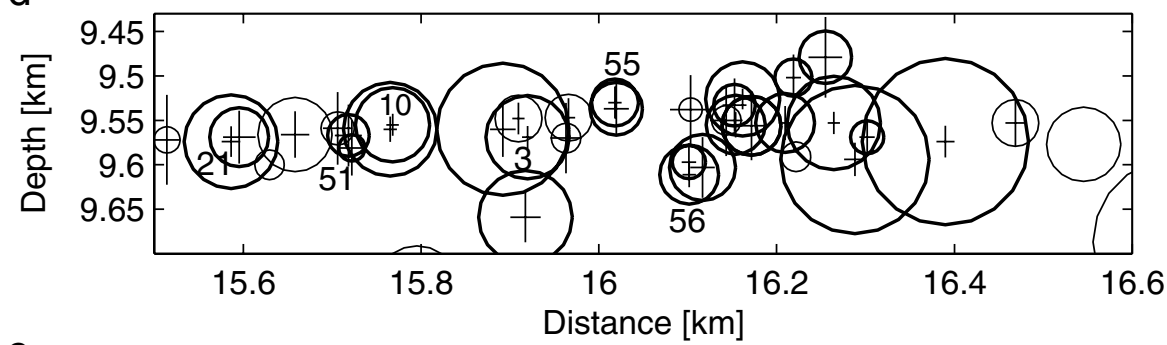

e

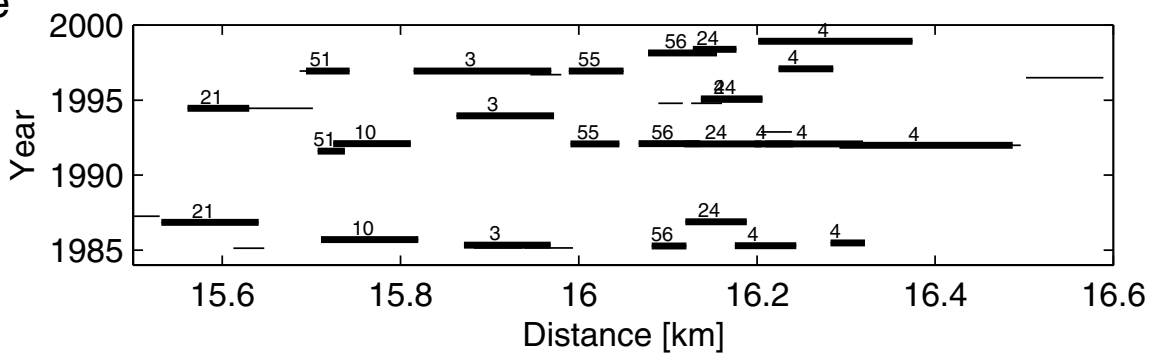

Figure 10. (a) (top) Surface creep rate along the Hayward Fault [after Lienkaemper et al., 2001]. Bars represent uncertainties. (bottom) Longitudinal cross section of seismicity as in Figure 5b. The location of repeating earthquake sequences are indicated by dots. For A, B, C, and D, see text. (b), (c), and (d) Zoom into locations of interest. (e) Time-distance plots of events shown in Figure 10d with rupture lengths displayed as a function of position along the streak versus date of occurrence. Thick circles in Figures $10 \mathrm{~b}-10 \mathrm{~d}$ and thick lines in Figure 10e denote repeating earthquakes. Numbers attached to sequences correspond to numbers in Table 1.

of the events in these clusters correlate, compared to $\sim 80 \%$ in clusters like El Cerrito or Fremont. The variation in faulting in the San Leandro-Oakland area persists to depth as shown by a reverse event (40) that occurred at a depth of $\sim 9 \mathrm{~km}$. Some events $(1,7,14$, 59, 29 in Figure 7) indicate strike-slip motion on northwest trending planes, while others $(11,12,13,24,38, \mathrm{~S} 3$ in Figure 7) exhibit right-lateral strike slip on a shallow northeast dipping plane. The M4.5 earthquake of 27 March 1984 appears to occur on the latter structure (large circle, located at $35 \mathrm{~km}$ distance and $6 \mathrm{~km}$ depth in the cross section of Figure 5b), although its focal mechanism (70 in Figure 7) indicates oblique right-lateral reverse motion.

[30] On the Mission Fault near Hayward the composite mechanisms for the two elongated multiplets $\mathrm{H} 1$ and $\mathrm{H} 2$ do not show evidence for a change in strike as observed in the relocated seismicity (Figures 5 and 8). This might indicate that the shallow seismicity occurs on en echelon structures (Figure 6). Near Union City one event (41 in Figure 7) indicates dip-slip motion. Near Fremont, composite focal mechanisms for multiplets F1 and F3 are consistent with a vertical fault plane. Events in multiplet F2 show compressional components, as does an event (53) that lies slightly to the east of the main fault (Figure 7).

\section{Repeating Earthquakes}

[31] Location uncertainties in the meter range for events that correlate permit us to investigate the existence of repeating 
Table 2. Repeating Earthquakes

\begin{tabular}{|c|c|c|c|c|c|c|}
\hline Date & Time, UT & Latitude & Longitude & Depth, km & Mag & ID \\
\hline 4 Nov. 1992 & $1135: 08.4$ & 38.03734 & -122.40607 & 6.332 & 1.7 & 63 \\
\hline 31 May 1998 & 0945:18.9 & 38.03734 & -122.40607 & 6.335 & 1.7 & 63 \\
\hline 6 May 1985 & 0108:05.1 & 37.91717 & -122.29480 & 2.729 & 1.8 & 7 \\
\hline 31 July 1993 & $1219: 04.6$ & 37.91710 & -122.29484 & 2.734 & 1.8 & 7 \\
\hline 19 Oct. 1997 & 172353.4 & 37.91710 & -122.29483 & 2.730 & 1.5 & 7 \\
\hline 3 March 1986 & $0518: 14.8$ & 37.93170 & -122.30281 & 4.975 & 1.5 & 19 \\
\hline 12 June 1991 & 0637:11.9 & 37.93180 & -122.30306 & 4.987 & 1.2 & 19 \\
\hline 28 Dec. 1986 & 0449:33.7 & 37.95211 & -122.30498 & 8.654 & 1.6 & 27 \\
\hline 3 June 1996 & $0715: 43.5$ & 37.95203 & -122.30446 & 8.657 & 1.8 & 27 \\
\hline 19 Feb. 1989 & 0232:17.9 & 37.95815 & -122.30934 & 9.275 & 1.5 & 42 \\
\hline 13 Sept. 1993 & $0801: 34.2$ & 37.95826 & -122.30910 & 9.301 & 1.5 & 42 \\
\hline 4 Nov. 1991 & $1054: 18.1$ & 37.86287 & -122.23271 & 9.621 & 1.6 & 52 \\
\hline 4 June 1997 & $0745: 38.6$ & 37.86300 & -122.23272 & 9.619 & 1.4 & 52 \\
\hline 19 Nov. 1991 & 1919:00.0 & 37.86592 & -122.23716 & 10.492 & 1.6 & 53 \\
\hline 29 May 1998 & $1829: 42.4$ & 37.86619 & -122.23728 & 10.510 & 1.7 & 53 \\
\hline 14 May 1992 & $2104: 41.0$ & 37.80116 & -122.19738 & 10.258 & 1.5 & 60 \\
\hline 15 May 1996 & 0411:37.0 & 37.80075 & -122.19734 & 10.291 & 1.9 & 60 \\
\hline 16 Oct. 1986 & $1120: 37.2$ & 37.75521 & -122.13379 & 7.837 & 2.4 & 23 \\
\hline 14 Jan. 1987 & $1307: 39.5$ & 37.75567 & -122.13376 & 7.882 & 2.4 & 23 \\
\hline 7 June 1990 & $2230: 58.1$ & 37.75551 & -122.13431 & 7.831 & 2.3 & 23 \\
\hline 20 Nov. 1994 & $1129: 46.7$ & 37.76992 & -122.19230 & 11.159 & 1.4 & 77 \\
\hline 4 June 1997 & 1028:07.4 & 37.76999 & -122.19217 & 11.127 & 1.1 & 77 \\
\hline 7 April 1984 & $1133: 36.0$ & 37.74735 & -122.14401 & 4.023 & 1.9 & 1 \\
\hline 26 July 1989 & $1045: 37.8$ & 37.74724 & -122.14414 & 4.026 & 1.9 & 1 \\
\hline 27 Feb. 1986 & $1347: 15.1$ & 37.72635 & -122.12038 & 3.993 & 1.3 & 18 \\
\hline 6 Nov. 1994 & $0555: 17.5$ & 37.72617 & -122.12043 & 4.010 & 1.1 & 18 \\
\hline 27 Jan. 1986 & 1935:30.4 & 37.71180 & -122.10612 & 5.302 & 1.7 & 15 \\
\hline 29 Jan. 1995 & 0753:39.0 & 37.71172 & -122.10620 & 5.286 & 1.4 & 15 \\
\hline 24 May 1988 & $1748: 27.1$ & 37.65070 & -122.03842 & 5.541 & 1.5 & 37 \\
\hline 24 Jan. 1998 & $1848: 29.5$ & 37.65039 & -122.03843 & 5.504 & 1.5 & 37 \\
\hline 22 Dec. 1990 & 0543:30.7 & 37.65084 & -122.04206 & 3.694 & 1.2 & 49 \\
\hline 9 Dec. 1994 & $1404: 32.1$ & 37.65083 & -122.04206 & 3.706 & 1.1 & 49 \\
\hline 31 Jan. 1986 & 0319:12.9 & 37.64750 & -122.04432 & 2.625 & 1.0 & 16 \\
\hline 25 Dec. 1987 & $1840: 10.3$ & 37.64749 & -122.04443 & 2.620 & 1.0 & 16 \\
\hline 18 Feb. 1988 & $1054: 21.7$ & 37.62963 & -122.01853 & 4.414 & 1.4 & 35 \\
\hline 21 Sept. 1997 & $0451: 42.0$ & 37.62947 & -122.01848 & 4.386 & 1.4 & 35 \\
\hline 14 Aug. 1990 & $0001: 43.7$ & 37.60884 & -121.99156 & 6.114 & 2.9 & 48 \\
\hline 6 Aug. 1993 & $2334: 49.9$ & 37.60875 & -121.99174 & 6.127 & 2.6 & 48 \\
\hline 4 Feb. 1992 & $2059: 32.8$ & 37.58722 & -121.96957 & 6.428 & 2.2 & 57 \\
\hline 12 Aug. 1997 & $2201: 59.6$ & 37.58712 & -121.96957 & 6.439 & 2.0 & 57 \\
\hline 23 Nov. 1984 & $1354: 33.3$ & 37.58833 & -121.97653 & 2.978 & 1.0 & 2 \\
\hline 12 July 1988 & 0720:14.0 & 37.58850 & -121.97652 & 2.978 & 1.3 & 2 \\
\hline 18 May 1985 & $1116: 49.7$ & 37.55590 & -121.93544 & 5.836 & 1.3 & 8 \\
\hline 11 Feb. 1990 & $1844: 11.7$ & 37.55581 & -121.93559 & 5.836 & 1.3 & 8 \\
\hline 29 July 1985 & $2210: 29.3$ & 37.55799 & -121.93536 & 6.224 & 1.2 & 9 \\
\hline 21 Oct. 1987 & $1937: 52.8$ & 37.55787 & -121.93531 & 6.229 & 1.1 & 9 \\
\hline 19 July 1985 & 0200:07.6 & 37.55767 & -121.93509 & 6.296 & 0.7 & 101 \\
\hline 27 May 1988 & $1211: 47.3$ & 37.55774 & -121.93521 & 6.305 & 1.2 & 101 \\
\hline 28 Nov. 1985 & $1221: 35.9$ & 37.54950 & -121.92518 & 6.079 & 0.9 & 13 \\
\hline 3 April 1987 & $1419: 32.9$ & 37.54958 & -121.92509 & 6.077 & 0.7 & 13 \\
\hline 15 Aug. 1997 & $1224: 33.2$ & 37.54943 & -121.92539 & 6.069 & 1.1 & 13 \\
\hline 28 March 1989 & 0019:16.3 & 37.53813 & -121.91744 & 5.616 & 1.4 & 43 \\
\hline 4 March 1995 & 0339:19.9 & 37.53810 & -121.91757 & 5.624 & 1.0 & 43 \\
\hline 11 Oct. 1997 & 0544:08.0 & 37.53803 & -121.91739 & 5.621 & 1.5 & 43 \\
\hline 11 Nov. 1985 & 0406:23.0 & 37.54270 & -121.92025 & 6.327 & 1.0 & 12 \\
\hline 23 July 1993 & $1205: 01.7$ & 37.54259 & -121.92048 & 6.301 & 1.0 & 12 \\
\hline 11 Oct. 1996 & 1833:51.6 & 37.54260 & -121.92041 & 6.317 & 1.2 & 12 \\
\hline 26 Oct. 1986 & $0426: 12.5$ & 37.52432 & -121.89282 & 6.106 & 0.8 & 25 \\
\hline 3 March 1991 & 0614:28.4 & 37.52448 & -121.89277 & 6.119 & 1.0 & 25 \\
\hline 5 Nov. 1988 & 0817:01.1 & 37.52381 & -121.89222 & 6.132 & 0.6 & 102 \\
\hline 29 Aug. 1998 & $2223: 48.8$ & 37.52386 & -121.89244 & 6.139 & 1.1 & 102 \\
\hline 26 Dec. 1986 & $0837: 15.5$ & 37.54004 & -121.91666 & 8.465 & 1.1 & 26 \\
\hline 22 Jan. 1995 & $1613: 41.6$ & 37.54006 & -121.91673 & 8.452 & 1.1 & 26 \\
\hline 21 March 1992 & 0135:34.7 & 37.54785 & -121.92418 & 6.800 & 1.4 & 58 \\
\hline 7 March 1996 & 0530:52.4 & 37.54775 & -121.92427 & 6.769 & 1.5 & 58 \\
\hline 2 April 1985 & $0557: 16.4$ & 37.87927 & -122.24462 & 9.569 & 1.9 & 3 \\
\hline 8 Nov. 1996 & 1915:06.4 & 37.87939 & -122.24493 & 9.560 & 2.3 & 3 \\
\hline 14 Aug. 1985 & $1801: 55.5$ & 37.88049 & -122.24548 & 9.560 & 2.0 & 10 \\
\hline 10 Jan. 1992 & $1439: 51.8$ & 37.88043 & -122.24554 & 9.555 & 1.8 & 10 \\
\hline 21 Feb. 1986 & 0239:40.8 & 37.86866 & -122.23788 & 9.882 & 1.6 & 17 \\
\hline 17 Aug. 1997 & 1841:54.2 & 37.86836 & -122.23787 & 9.856 & 1.3 & 17 \\
\hline 5 Oct. 1986 & $1039: 20.4$ & 37.88197 & -122.24637 & 9.574 & 2.0 & 21 \\
\hline 12 May 1994 & 0858:13.8 & 37.88184 & -122.24642 & 9.569 & 1.6 & 21 \\
\hline
\end{tabular}


Table 2. (continued)

\begin{tabular}{|c|c|c|c|c|c|c|}
\hline Date & Time, UT & Latitude & Longitude & Depth, km & Mag & ID \\
\hline 5 July 1991 & 0219:17.4 & 37.88083 & -122.24572 & 9.581 & 0.9 & 51 \\
\hline 9 Nov. 1996 & 0617:11.9 & 37.88080 & -122.24585 & 9.567 & 1.3 & 51 \\
\hline 29 Dec. 1991 & $1240: 04.2$ & 37.87840 & -122.24422 & 9.530 & 1.4 & 55 \\
\hline 9 Nov. 1996 & 0041:12.6 & 37.87835 & -122.24427 & 9.537 & 1.5 & 55 \\
\hline 8 March 1985 & $1705: 21.4$ & 37.87783 & -122.24360 & 9.597 & 1.1 & 56 \\
\hline 7 Jan. 1992 & $1212: 02.5$ & 37.87783 & -122.24360 & 9.611 & 1.6 & 56 \\
\hline 22 Jan. 1998 & 0029:48.1 & 37.87769 & -122.24354 & 9.603 & 1.7 & 56 \\
\hline
\end{tabular}

earthquakes. Presumably, these earthquakes are caused by patches of brittle material (asperities) on the fault that fail repeatedly as they are loaded by creep on the surrounding surface [Vidale et al., 1994; Nadeau et al., 1995]. In theory, repeating events will have identical waveforms due to identical source mechanisms, ray paths, and receiver response. Real seismograms, however, may exhibit small variations in the shape of the signals that reflect changes in source, path, receiver characteristics, and/or noise. Although two events might be perfectly colocated, the signals may be incoherent due to noise in the data. On the other hand, two events that are separated in space, could produce highly coherent waveforms if they occur in a homogenous velocity field. Although the degree of similarity between two phases at a common station can be used as a rough measure of the closeness of two events [Nadeau et al., 1995; Menke, 1999], it does not translate directly into the distance between the events. In particular, relative location uncertainties cannot easily be estimated from waveform similarity alone.

[32] Given these problems, we search for repeating events in the 1984-1998 seismicity by investigating the separation distance between centroids determined from phase correlation measurements. We select events that have small relative location uncertainites, with probable overlap of their source areas $(>50 \%)$, assuming a 3-MPa stress drop and magnitude differences smaller than 0.5. The time intervals between successive events show a broad distribution between 1 and 11 years with a peak around 5.5 years and a sharp peak for intervals $<1$ year (Figure 9). Thirty-four percent of the intervals are $<1$ month, and $27 \%$ are $<1$ day (Figure 9 , inset). Time intervals of $<1$ month are approximately exponentially distributed, suggesting that they represent an aftershock process. Those events with short time separation may, in fact, have little or no overlap, given our lack of control on source dimension. To form sequences of repeating earthquakes, we only consider events with recurrence intervals $>1$ by removing the smaller-magnitude event that precedes or follows another event by $<1$ month in each sequence.

[33] The locations of these sequences on the fault surface are shown in Figure 10a. A detailed look at the relative location of the repeating events shows that some sequences are formed by events that lie virtually on top of each other (Figure 10b), whereas others include events that are possibly slightly separated in space (Figure 10c). Events of the latter type could be distinct if their stress drop is $>30$ bars. Unfortunately, not all of the hypocentroids are precise enough to test this possibility. Some repeating sequences occupy distinct, isolated areas on the fault plane (Figures 10b and 10c), others are located in close proximity to other events (Figure 10d, left part of streak). Some sequences may occur within groups of scattered hypocenters that include fore/aftershock sequences, mostly within clusters or streaks (Figure 10d, right part of the streak). The source parameters for the first two types of repeating earthquakes are listed in Table 2. There are 31 sequences that have two repeating events and five sequences that have three events. The sequences with three events typically show a larger variation in their magnitudes.

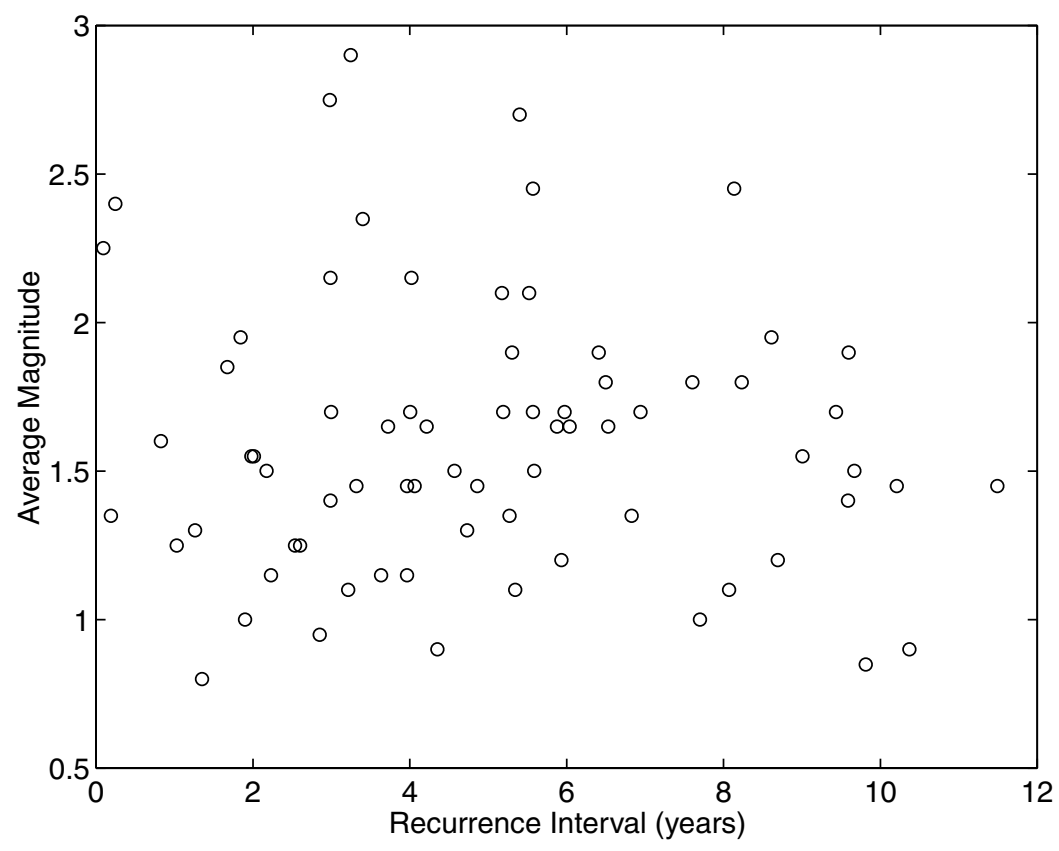

Figure 11. Recurrence intervals plotted against the average magnitude between all pairs of repeating events along the Hayward and Mission Faults. No correlation between magnitude and recurrence interval is observed. 
[34] From Figure 10a we see that repeating events are most common at shallow depth, between $\sim 2$ and $7 \mathrm{~km}$. Surface creep measurements [Lienkaemper et al., 2001] (Figure 10a) and geodetic surveys indicate that the fault is creeping to $\sim 5 \mathrm{~km}$ depth [Savage and Lisowski, 1993; Lienkaemper and Galehouse, 1998; Bürgmann et al., 1998]. The shallow repeating events can be interpreted to represent strong patches undergoing stick-slip failure as they are continuously loaded by creep on the surrounding fault plane. Multiplets with higher repeat rates (e.g., multiplet 7 with three events of $M 1.8, M 1.8$, and $M 1.5$ in the 15 -year observational period, Figure 10a and 10b) located at the shallowest depths, suggesting a positive creep rate gradient toward the surface.

[35] Repeating events at greater depth rarely occur as isolated sources. Instead, they predominantly occur within the streaks. A time-distance plot of the events along streak B1 (Figure 10e) shows a large variability of recurrence intervals and magnitude. Although there is no clear pattern emerging from Figure 10e, a possible progression of events along the streak can be observed that seems plausible from a triggering viewpoint since these events are all more or less in a line. Also, a clearer pattern may be hidden in a seismic gap observed between 1987 and 1992 that may be related to stress changes on the Hayward Fault caused by the 1989 M7.1 Loma Prieta earthquake [Reasenberg and Simpson, 1992; Lienkaemper et al., 1997].

[36] In contrast to creeping portions of the San Andreas and Calaveras Faults where repeating earthquakes are the norm and occur throughout the slipping fault surface [Nadeau et al., 1995; Schaff et al., 1998; Rubin et al., 1999], the Hayward Fault less frequently exhibits repeating behavior. On the Parkfield section of the San Andreas Fault, repeating events of $M \sim 1.4$ have been found to occur at a rate of about once per year or two [Nadeau and Johnson, 1998], with a creep rate that is $\sim 4$ times the average creep rate of the Hayward Fault. Thus the repeat rate for source 7 (Figure 10b), when scaled by creep rate, approximately agrees with San Andreas Fault recurrence rate. Comparisons, however, are hampered by the fact that repeat rates on the Hayward Fault appear to be less regular than on the San Andreas Fault and do not correlate with magnitude (Figure 11).

\section{Discussion and Conclusion}

[37] The seismicity rate of the Hayward Fault is substantially lower than that of the creeping central Calaveras Fault to its south, whether measured by the contemporary microearthquake rate or twentieth century moderate magnitude activity [Oppenheimer et al., 1990]. The difference in seismicity rates cannot be explained by the difference in creep rates ( 6 versus $15 \mathrm{~mm} / \mathrm{yr}$ ). This suggests to us that there is a more fundamental difference between them. We suggest that the large aseismic areas on the Hayward Fault plane between $\sim 5$ and $10 \mathrm{~km}$ are either locked or retarded (areas A, B, C, $\mathrm{D}$ in Figure 10a). Studies on pre- and post-main shock seismicity on the Calaveras Fault [Bakun et al., 1986; Oppenheimer et al., 1990] and along the San Andreas Fault segment that ruptured during the 1989 Loma Prieta earthquake [Olson, 1990; Oppenheimer, 1990] have shown that sections of the fault that rupture during main shocks exhibit little on-fault earthquake activity in between the time of major events. The circular hole near Fremont (area D), for example, could produce a $M \sim 5.5$ event (considering 3-MPa stress drop) or larger if it ruptured into the adjacent aseismic areas to the northwest near Union City and Hayward (area C). Although several large historic earthquakes have occurred near the Mission trend [Andrews et al., 1993; Bakun, 1999], uncertainties in their locations are too large to determine if one or more of them actually occurred on the Mission trend.

[38] On the northern Hayward Fault, creep rates may vary with depth. A relatively high rate of creep might encompass the shallow repeating events, while large aseismic areas (within area A) between the streaks suggest zones of locking. In this interpretation the streaks are close to the upper and lower boundaries of the proposed seismogenic zone. If correct, stress concentrations due to fault creep above and below the locked zone may explain the generation and localization of the streaks. Such stress concentrations are highest if the zone between the streaks is frictionally locked.

[39] Interferometric synthetic aperture radar (InSAR) and GPS data analyzed by Bürgmann et al. [2000], on the other hand, suggest a freely slipping northern Hayward Fault (NW of km 25 in Figure 10a). Their model favors fault creep of $\sim 7 \mathrm{~mm} / \mathrm{yr}$ to depths $>6 \mathrm{~km}$. In their model, however, a locked fault below $6 \mathrm{~km}$ would decrease the creep rate only by $\sim 7 \%$, which is less than the mean of the uncertainties of the creep rate measurements. Bürgmann et al. [2000] supported their argument of a freely slipping fault by analyzing repeating earthquakes to infer the distribution of subsurface fault creep rates [Nadeau and McEvilly, 1999]. They determined a creep rate of 5-7 mm/yr from repeating earthquakes with catalog locations around 5.7 and $9.8 \mathrm{~km}$ depth near El Cerrito and Berkeley (one of their repeating earthquake locates at $7 \mathrm{~km}$ depth). The relocated hypocenters in Figure 10a show that there is no evidence for repeating earthquakes between 6 and $9 \mathrm{~km}$ depth. Thus the creep rate of Bürgmann et al. [2000] might represent the creep rate at the upper and lower boundary of a locked zone (area A, Figure 10a).

[40] The Hayward Fault is one member of a series of linked strike-slip faults that parallels the San Andreas Fault from the Calaveras-San Andreas junction to near the Mendocino Triple Junction $400 \mathrm{~km}$ to the northwest. Castillo and Ellsworth [1993] suggested that the Hayward Fault reflects a mature stage of fault development from the systematic evolution of seismically defined structures within this fault system from its northwest end (youngest) to its southeast end (oldest). This hypothesis is strengthened by the streaks described by Waldhauser et al. [1999], who argued that the streaks on the northern Hayward Fault might represent longlived structures created by a wear process. The absence of such streaks on the Mission trend may indicate that this structure is relatively young or that is has been reactivated. The fault-normal cross sections in Figure $5 \mathrm{~b}$ show that the Mission trend seismicity near Union City and to the south does not underlie the surface trace of the Hayward Fault, suggesting an independent structure in this area. North of Union City to near San Leandro the seismicity seems to occur on the Chabot Fault, a feature that extends $\sim 1 \mathrm{~km}$ to the northeast and parallel to the Hayward Fault and is recognized by R. W. Graymer (Neogene development of the Hayward Fault zone: A different perspective on an active strike-slip fault, submitted to Tectonics, 2001, hereinafter referred to as Graymer, submitted manuscript, 2001) as part of a broadened zone of the Hayward Fault. Double-difference locations near Hayward, where the intersection between the Mission and the Chabot Fault takes place, show that the shallow seismicity strikes more westerly than the seismicity at greater depth (best seen in Figure 6), suggesting that the intersection of the Mission trend with the Hayward Fault may involve substructures such as the Chabot Fault. It is possible that we see a migration process in which new strands are generated, old strands are reactivated, or the Mission trend and the southern Hayward Fault interact in their activity.

[41] Andrews et al. [1993] placed the Mission trend in a left step over between the Calaveras and Hayward Faults, with a structure along the Mission trend transferring slip from the Calaveras Fault onto the northern Hayward Fault. Assuming pure strike-slip on the Hayward Fault and the Calaveras Fault, they argue for a blind dipping structure to satisfy the geometric constraint of convergence. They interpret the apparent absence of dip on the structure as defined by the Mission seismicity trend as indicating an accumulating dip-slip moment deficit that will eventually be released in a large earthquake, thus making the Mission step over more likely to rupture in large earthquakes than previously assumed. The relocated seismicity along the Mission trend, on 
the other hand, indicates that at least some compression is being accommodated. Fault-normal cross sections (Figure $5 \mathrm{~b}$ ) show that the dip changes from near vertical near Fremont to $\sim 75^{\circ}$ southeast dipping near Hayward. A few thrust events are observed along the entire Mission trend, the most notable near San Leandro where we observe shallow dip-slip events (including five $M>3.0$ events) that occur on a $10^{\circ}$, northwest dipping structure (Figure 7). The contemporary seismicity on the Mission trend, however, is not able accommodate enough slip to compensate the compressional forces evident in the topographic expression.

[42] The wide range of complex faulting associated with the intersection of the Mission trend and the Hayward Fault might represent stress accumulation that arises from slip transfer along the Mission trend between the Calaveras and the Hayward Faults. Similar complex patterns are observed in zones of fault bends where stress concentrations at the tip of the fault are relieved by complex faulting patterns [King and Nábelek, 1985]. In addition to geometric complexity, faulting in this area might be complicated or controlled by structural heterogeneities, in particular, by a gabbroic body near San Leandro that steeply dips into the fault zone from its western side [Ponce et al., 1998; Graymer, submitted manuscript, 2001]. The off-fault seismicity near Berkeley might also be an indication that the transfer of slip onto the northern Hayward Fault is not occurring in a smooth fashion, as irregularities on the surface of the northern Hayward Fault and possibly locked patches act as asperities and distribute slip away from the main trace.

[43] Acknowledgments. We thank Bob Simpson, David Oppenheimer, Andy Michael, Allan Rubin, and two anonymous reviewers for their constructive comments on the manuscript. We greatly benefited from fruitful discussions within the USGS Hayward Fault Working Group. Russ Graymer is thanked for leading a elucidating field trip to the Hayward Fault. We are grateful to the staff at the NCSN for making their data available. We thank Paul Reasenberg and Bruce Julian for providing the software to create Figure 6.

\section{References}

Andrews, D. J., D. H. Oppenheimer, and J. J. Lienkaemper, The Mission link between the Hayward and Calaveras Faults, J. Geophys. Res., 98, 12,083-12,095, 1993.

Bakun, W. H., Seismic activity of the San Francisco Bay region, Bull. Seismol. Soc. Am., 89, 764-784, 1999

Bakun, W. H., and C. M. Wentworth, Estimating earthquake location and magnitude from seismic intensity data, Bull. Seismol. Soc. Am., 87, 1502-1521, 1997.

Bakun, W. H., G. C. P. King, and R. S. Cockerham, Seismic slip, aseismic slip, and the mechanics of repeating earthquakes on the Calaveras Fault, California, in Earthquake Source Mechanics, Geophys. Monogr. Ser., vol. 37, edited by S. Das, J. Boatwright, and C. H. Scholz, pp. 195-207, AGU, Washington, D. C., 1986.

Borchardt, G., S. E. Hirschfeld, J. J. Lienkaemper, P. McClellan, and I. G. Wong (Eds.), Proceedings of the Second Conference on Earthquake Hazards in the Eastern San Francisco Bay Area, Spec. Publ. Calif. Div. Mines Geol., 113, 1992.

Bürgmann, R., E. Fielding, and J. Sukhatme, Slip along the Hayward Fault, California, estimated from space-based synthetic aperture radar interferometry, Geology, 26, 559-562, 1998.

Bürgmann, R., D. Schmidt, R. M. Nadeau, M. d'Alessio, E. Fielding, D. Manaker, T. V. McEvilly, and M. H. Murray, Earthquake potential along the northern Hayward Fault, California, Science, 289, 1178-1182, 2000.

Castillo, D. A., and W. L. Ellsworth, Seismotectonics of the San Andreas Fault system between Point Arena and Cape Mendocino in northern California: Implications for the development and evolution of a young transform, J. Geophys. Res., 98, 6543-6560, 1993.

Chester, F. M., J. P. Evans, and R. L. Biegel, Internal structure and weakening mechanisms of the San Andreas Fault, J. Geophys. Res., 98, 771$786,1993$.

Ellsworth, W. L., J. A. Olson, L. N. Shjio, and S. M. Marks, Seismicity and active faults in the eastern San Francisco Bay region, Spec. Publ. Calif. Div. Mines Geol., 62, 83-91, 1982.

Fréchet, J., Sismogenèse et doublets sismiques, thèse d'Etat, 206 pp., Univ. Sci. et Méd. de Grenoble, Grenoble, France, 1985.
Got, J.-L., J. Fréchet, and F. W. Klein, Deep fault plane geometry inferred from multiplet relative relocation beneath the south flank of Kilauea, J. Geophys. Res., 99, 15,375-15,386, 1994.

Graymer, R. W., D. L. Jones, and E. E. Brabb, Geologic map of the Hayward Fault zone, Contra Costa, Alameda, and Santa Clara Counties, California: A digital database, U.S. Geol. Surv. Open File Rep., 95597,1995

Hayward Fault Paleoearthquake Group, Timing of paleoearthquakes on the northern Hayward Fault-Preliminary evidence in El Cerrito, California, U.S. Geol. Surv. Open File Rep., 99-318, 1999.

King, G., and J. Nábelek, Role of fault bends and the initiation and termination of earthquake rupture, Science, 228, 984-987, 1985.

King, G., D. Oppenheimer, and F. Amelung, Block versus continuum deformation in the western United States, Earth Planet. Sci. Lett., 128, $55-$ 64, 1994.

Lawson, A. C., The California earthquake of April 18, 1906, in Report of the State Earthquake Investigation Commision, vol. 1, Carnegie Inst. of Washington, Washington, D. C., 1908.

Lienkaemper, J. J., and G. Borchardt, Hayward Fault: Large earthquakes versus surface creep, in Proceedings of the Second Conference on Earthquake Hazards in the Eastern San Francisco Bay Area, edited by G. Borchardt et al., Spec. Publ. Calif. Div. Mines Geol., 113, 101-110, 1992.

Lienkaemper, J. J., and J. S. Galehouse, New evidence doubles the seismic potential of the Hayward Fault, Seismol. Res. Lett., 69, 519-523, 1998. Lienkaemper, J. J., G. Borchardt, and M. Lisowski, Historic creep rate and potential for seismic slip along the Hayward Fault, California, J. Geophys. Res., 96, 18,261-18,283, 1991.

Lienkaemper, J. J., J. S. Galehouse, and R. W. Simpson, Creep response of the Hayward Fault to stress changes caused by the Loma Prieta earthquake, Science, 276, 2014-2016, 1997.

Lienkaemper, J. J., J. S. Galehouse, and R. W. Simpson, Long-term monitoring of creep rate along the Hayward Fault and evidence for a lasting creep response to 1989 Loma Prieta earthquake, Geophys. Res. Lett., 28, 2265-2268, 2001.

Menke, W., Using waveform similarity to constrain earthquake locations, Bull. Seismol. Soc. Am., 89, 1143-1146, 1999.

Nadeau, R. M., and L. R. Johnson, Seismological studies at Parkfield, VI, Moment release rates and estimates of source parameters for small repeating earthquakes, Bull. Seismol. Soc. Am., 88, 790-814, 1998.

Nadeau, R. M., and T. V. McEvilly, Fault slip rates at depth from recurrence intervals of repeating microearthquakes, Science, 285, 718-721, 1999.

Nadeau, R. M., W. Foxall, and T. V. McEvilly, Clustering and periodic recurrence of microearthquakes on the San Andreas Fault at Parkfield, California, Science, 267, 503-507, 1995.

Olson, J. A., Seismicity in the twenty years preceding the Loma Prieta, California, earthquake, Geophys. Res. Lett., 17, 1429-1432, 1990.

Oppenheimer, D. H., Aftershock slip behavior of the 1989 Loma Prieta, California earthquake, Geophys. Res. Lett., 17, 1199-1202, 1990.

Oppenheimer, D. H., P. A. Reasenberg, and R. W. Simpson, Fault plane solutions for the 1984 Morgan Hill, California, earthquake sequence: Evidence for the state of stress on the Calaveras Fault, J. Geophys. Res., 93, 9007-9026, 1988.

Oppenheimer, D. H., W. H. Bakun, and A. G. Lindh, Slip partitioning of the Calaveras Fault, California, and prospects for future earthquakes, J. Geophys. Res., 95, 8433-8498, 1990.

Oppenheimer, D. H., I. G. Wong, and F. W. Klein, The seismicity of the Hayward Fault, California, in Proceedings of the Second Conference on Earthquake Hazards in the Eastern San Francisco Bay Area, edited by G. Borchardt et al., Spec. Publ. Calif. Div. Mines Geol., 113, 91-100, 1992.

Paige, C. C., and M. A. Saunders, LSQR: Sparse linear equations and least squares problems, ACM Trans. Math. Software, 8(2), 195-209, 1982.

Ponce, D. A., T. G. Hildenbrand, R. C. Jachens, C. W. Roberts, and P. E. Fahringer, Gravity and magnetic anomalies along the Hayward Fault and their relation to earthquake seismicity, California (abstract), Eos Trans. $A G U, 79(45)$, Fall Meet. Suppl., F594, 1998.

Poupinet, G., W. L. Ellsworth, and J. Fréchet, Monitoring velocity variations in the crust using earthquake doublets: An application to the Calaveras Fault, California, J. Geophys. Res., 89, 5719-5731, 1984.

Radbruch-Hall, D. H., Map showing recently active breaks along the Hayward Fault zone and the southern part of the Calaveras Fault zone, U.S. Geol. Surv. Misc. Invest. Ser., Map, I-813, 1974.

Reasenberg, P., and D. Oppenheimer, FPFIT, FPPLOT, and FPPAGE: FORTRAN computer programs for calculating and displaying earthquake fault-plane solutions, U.S. Geol. Surv. Open File Rep., 85-739, 109, 1985.

Reasenberg, P. A., and R. W. Simpson, Response of regional seismicity to the static stress change produced by the Loma Prieta earthquake, Science, $255,1687-1690,1992$. 
Rubin, A. M., D. Gillard, and J.-L. Got, Streaks of microearthquakes along creeping faults, Nature, 400, 635-641, 1999.

Savage, J. C., and M. Lisowski, Inferred depth of creep on the Hayward Fault, central California, J. Geophys. Res., 98, 787-793, 1993.

Schaff, D. P., G. C. Beroza, and B. E. Shaw, Postseismic response of repeating aftershocks, Geophys. Res. Lett., 25, 4549-4552, 1998.

Simpson, R. W., Watching the Hayward Fault, Science, 289, 1147-1148, 2000.

Toppozada, T. R., and G. Borchardt, Re-evaluation of the 1836 'Hayward Fault' earthquake and the 1838 San Andreas Fault earthquake, Bull. Seismol. Soc. Am., 88, 140-159, 1998

Vidale, J. E., W. L. Ellsworth, A. Cole, and C. Marone, Variations in rupture process with recurrence interval in a repeated small earthquake, Nature, $368,624-626,1994$

Waldhauser, F., hypoDD: A computer program to compute double-difference hypocenter locations, U.S. Geol. Surv. Open File Rep., 01-113, 25 pp., 2001

Waldhauser, F., and W. L. Ellsworth, A double-difference earthquake location algorithm: Method and application to the northern Hayward Fault, California, Bull. Seismol. Soc. Am., 90, 1353-1368, 2000.

Waldhauser, F., W. L. Ellsworth, and A. Cole, Slip-parallel seismic lineations along the northern Hayward Fault, California, Geophys. Res. Lett., 26, 3525-3528, 1999.

Williams, P. L., Geologic record of southern Hayward Fault earthquakes, in
Proceedings of the Second Conference on Earthquake Hazards in the Eastern San Francisco Bay Area, edited by G. Borchardt et al., Spec. Publ. Calif. Div. Mines Geol., 113, 171-179, 1992.

Wong, I. G., and M. A. Hemphill-Haley, Seismicity and faulting near the Hayward and Mission Faults, in Proceedings of the Second Conference on Earthquake Hazards in the Eastern San Francisco Bay Area, edited by G. Borchardt et al., Spec. Publ. Calif. Div. Mines Geol., 113, 207-215, 1992.

Working Group on California Earthquake Probabilities (WGCEP), Earthquake probabilities in the San Francisco Bay region: 2000 to 2030-A summary of findings, U.S. Geol. Surv. Open File Rep., 99-517, 1999.

Yu, E., and P. Segall, Slip in the 1868 Hayward earthquake from the analysis of historical triangulation data, J. Geophys. Res., 101, 16,101-16,118, 1996.

Zoback, M. D., et al., New evidence on the state of stress of the San Adnreas Fault system, Science, 238, 1105-1111, 1987.

W. L. Ellsworth, U.S. Geological Survey, 345 Middlefield Road, MS 977, Menlo Park, CA 94025, USA. (ellsworth@usgs.gov)

F. Waldhauser, Lamont-Doherty Earth Observatory of Columbia University, 61 Route 9W, Palisades, NY 10964, USA. (felixw@ldeo. columbia.edu) 
a)

CATALOG LOCATIONS 1984-1998

Map View
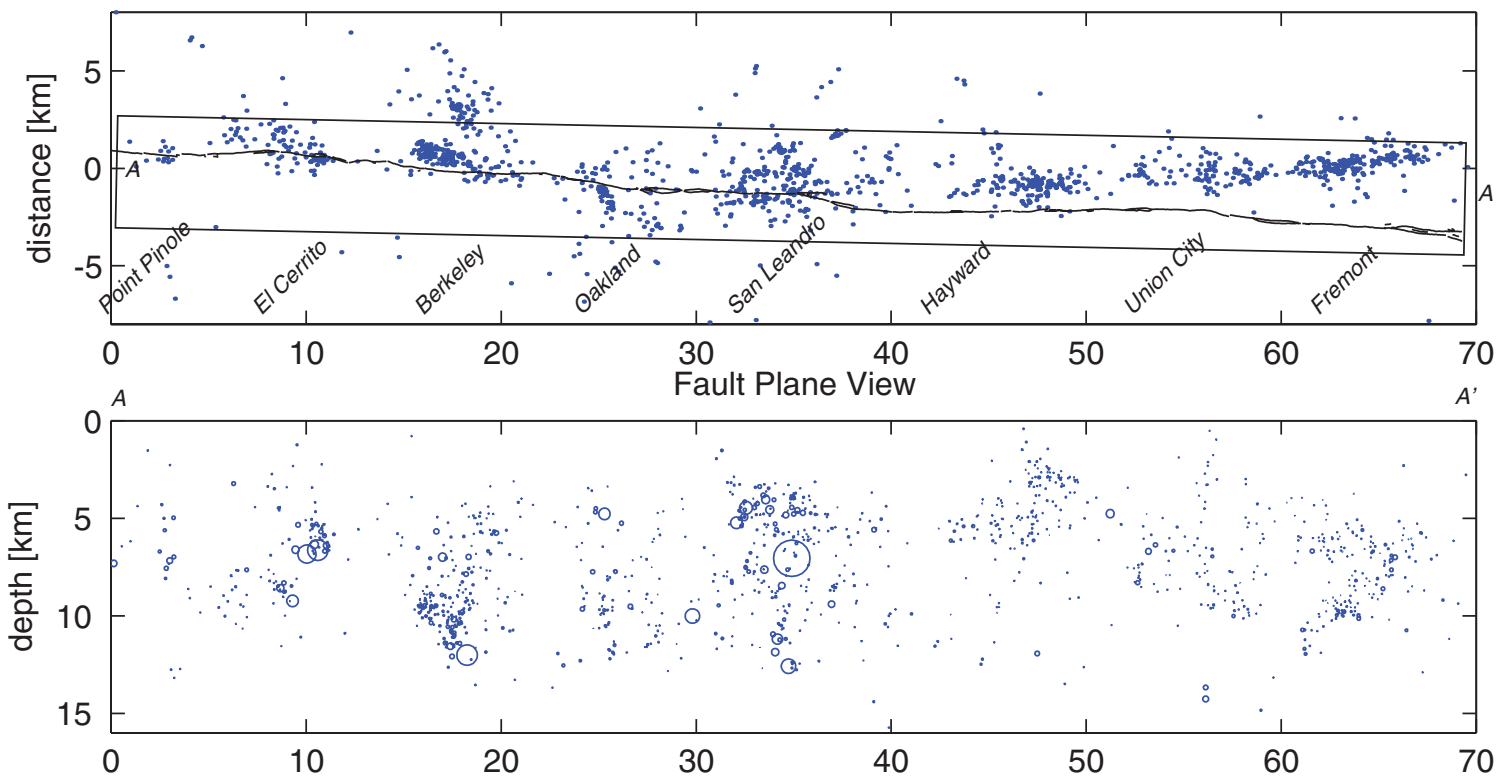

b)

AFTER RELOCATION

Map View
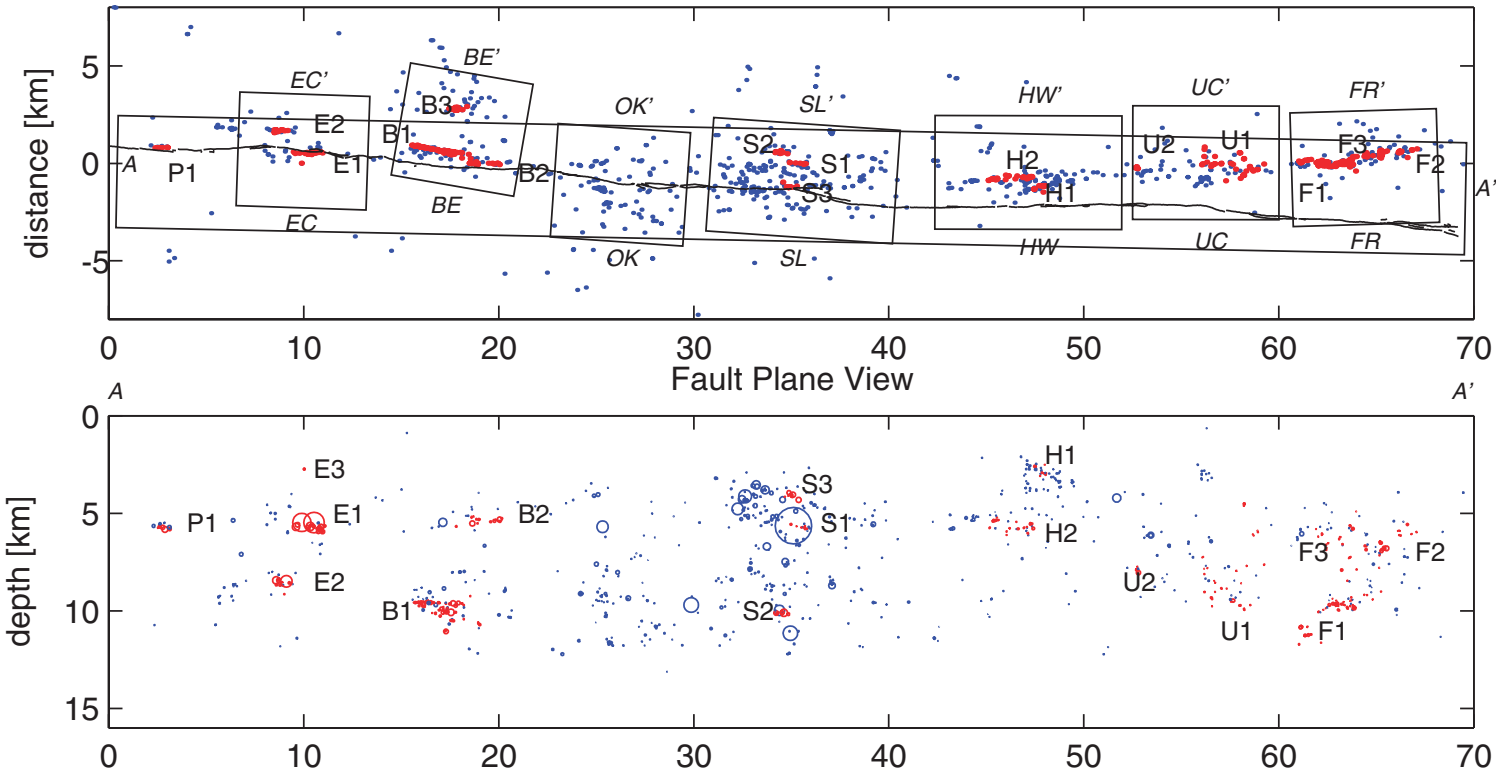

Fault Normal View
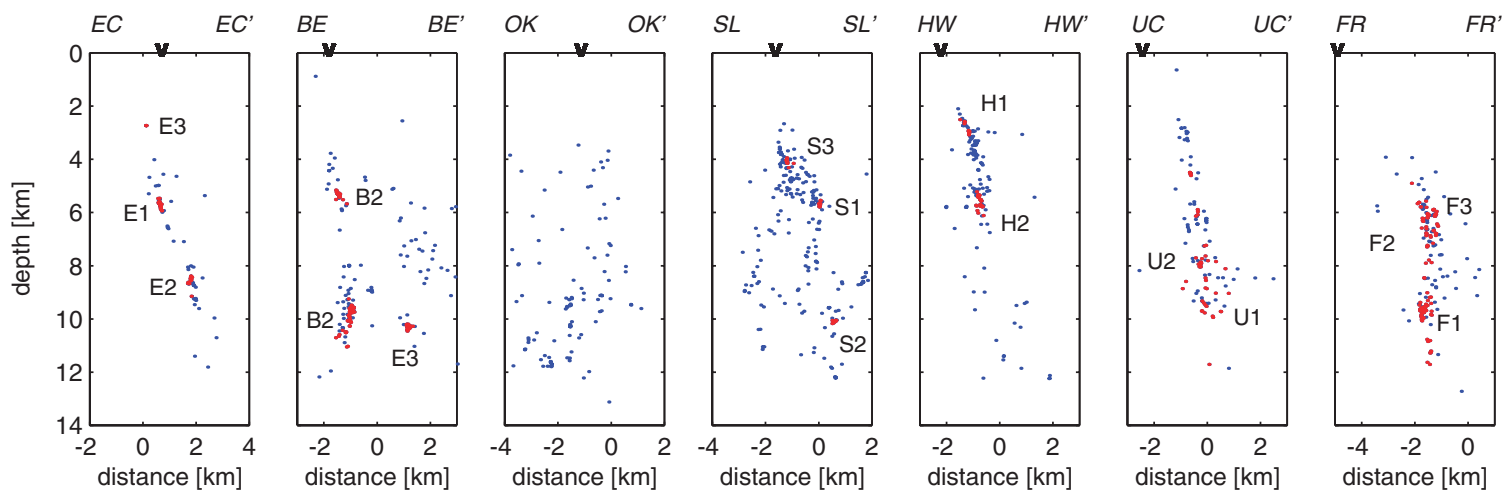

ESE $3-6$ 
JOURNAL OF GEOPHYSICAL RESEARCH, VOL. 107, NO. B3, 10.1029/2000JB000084, 2002

Figure 5. (opposite) (a) NCSN locations and (b) double-difference locations of events recorded between 1984 and 1998, including catalog $P$ and cross-correlation $P$ and $S$ wave data. Map view (rotated so that fault trace points east-west) and longitudinal cross sections (in kilometers from Point Pinole) are shown. Fault-normal cross sections are shown for the relocated seismicity only. Earthquakes in longitudinal cross sections are plotted as circles of dimensions appropriate for their magnitude assuming a 30-bar constant stress drop source. Boxes in map views include events shown in cross sections. In Figure 5b, groups of eight or more correlated events are indicated in red and labeled (see text for details). In fault-normal cross sections, "v" indicates the surface trace of the Hayward Fault. 